تضيق الفجوة بين الدول الصناعية والدول النامية

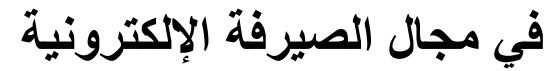

دراسة نظرية تحليلية

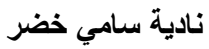 \\ مدرس مساعد-قسم علوم مالية ومصرية خصنية \\ كلية الإدارة والاقتصاد-جامعة الموصل مالية \\ nadiahther@yahoo.com
}

\begin{abstract}
المستخلص

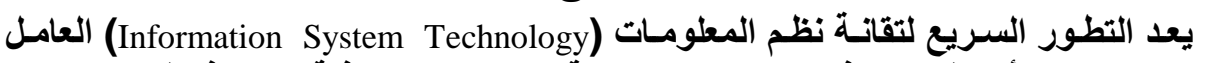

الرئيس وراء تغيير أنماط العمل في المؤسسات المالية ولاسيما المئلمات المصرفية منها، فالطلب المتزايد

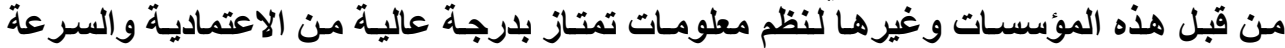

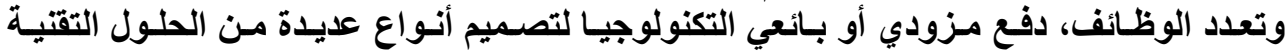
تتواعم مع العديد من المتطلبات العملية.

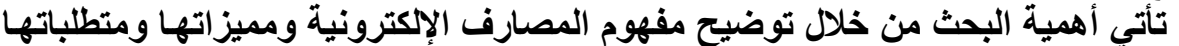

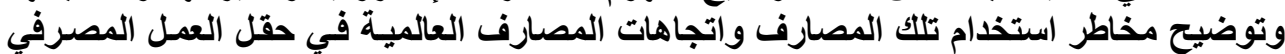

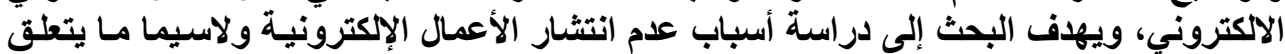

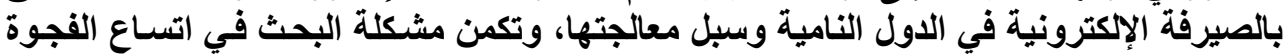

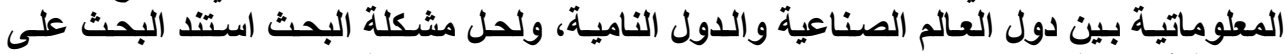

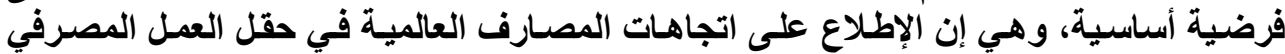

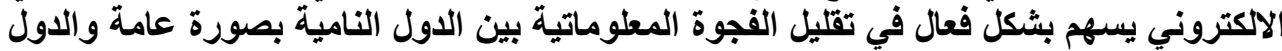

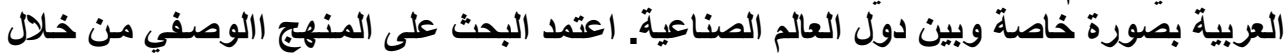

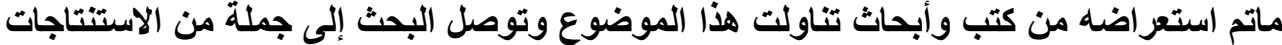




\title{
The Reduction of the Gap between the Industrial and the Developing Countries in the Field of Electronic Banking: A Theoretical Analytic Study
}

\author{
Nadia S. Khudhir \\ Assistant Lecturer \\ College of Administration and Economics \\ University of Mosul
}

\begin{abstract}
The rapid progress in information systems technology is considered to be the main factor of changing the work patterns in financial institutions especially the banking ones. So, the increasing demand of these institutions is usually characterized with a high dependency, rapidness and multi functional information systems that may encourage the technology providers to redesign various techniques suitable for the practical requirements.

The importance of this research came to explain the illustration of the electronic banking concept. The characteristics, requirements and the risks of using these banks and the directions of the universal banks in the field of electronic banking were demonstrated. The current paper is targeted to study the reasons of electronic non - spread works especially that belongs to the electronic banking in growing countries and the methods of treatment whereas the problem of the study is in the expanding of the informatics gap between the industrial developed countries and growing the countries. A hypothesis has been delineated in this paper for the acquaintance of the global banks trends in the electronic banking work contributes actively in reducing the informatics gap between the developing countries and the industrial developed countries. The paper depends on the descriptive method the books and researches belong to the subject. The paper has conclusions and recommendations.
\end{abstract}

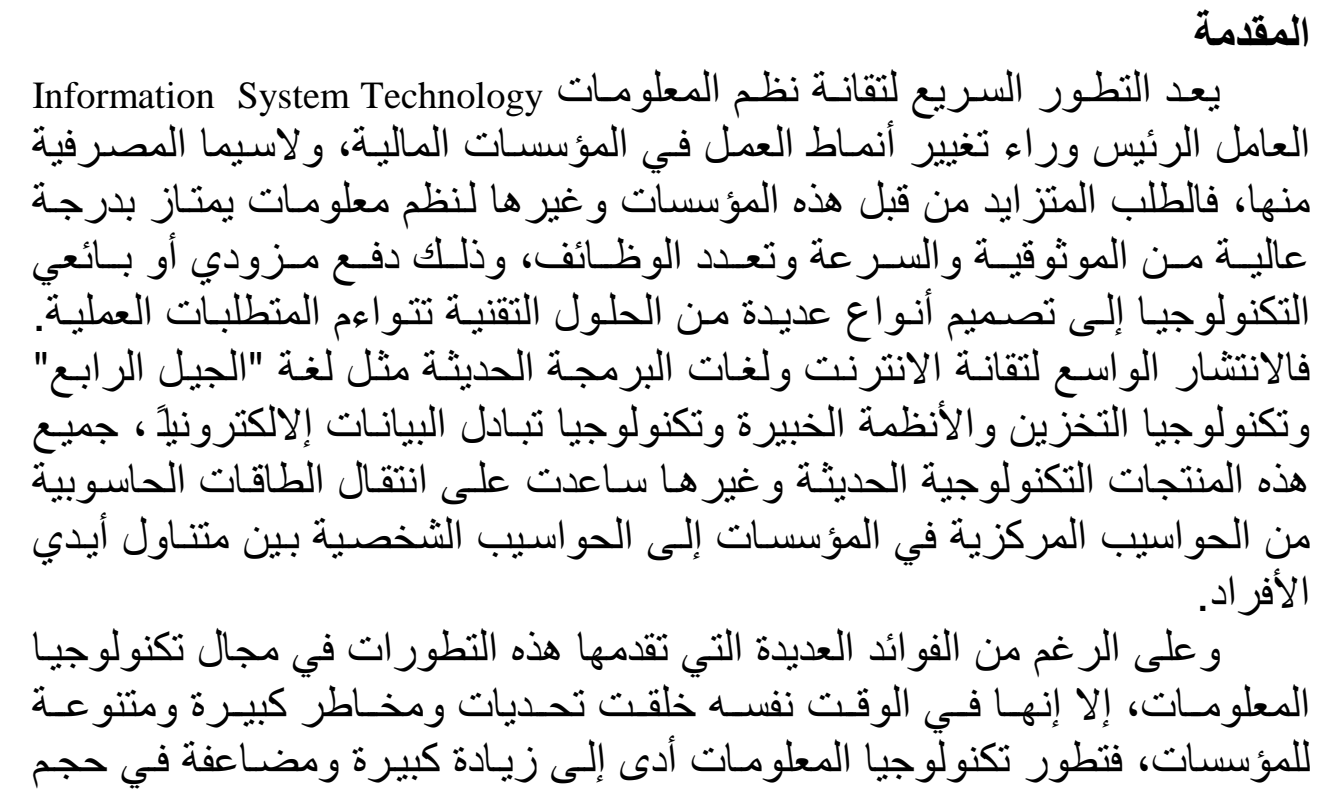


تضيق الفجوة بين الدول الصناعية والدول النامية... _ _ [101]

البيانات و المعلومات المتو افرة، وزيـادة في سر عة معالجتهـا ومر اقبتها، الأمـر الذي أدى إلى رفع درجة صعوبة العمل وتعقيده.

تكمن مشكلة البحث في اتسـاع الفجوة المعلوماتيـة بين دول العـالم الصـناعية

مشكلة البحث

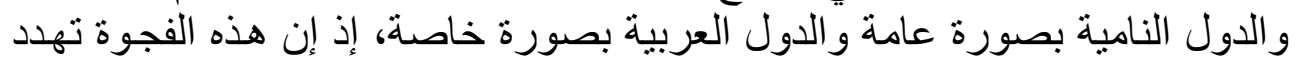
بتهميش الدول غير المعلوماتية و إقصائها عن الاقتصاد العالمي القائم على المعلومات فاه و المعرفة.

تأتي أهمية البحث من خلال توضيح مفهوم المصسارف الإلكترونيـة ومميز اتها

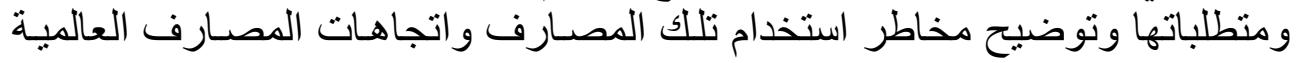
في حقل العمل المصرفي الالكتروني.

يهدف البحث إلى دراسة أسباب عدم انتشار الأعمال الإلكترونية، و لاسيما فيما

\section{هدف البحث} يتعلق بالصيرفة الإلكترونية في الدول النامية وسبل معالجتها.

يمكن تحديد فرضية البحث من خلال المشكلة المؤشرة بالاتي:

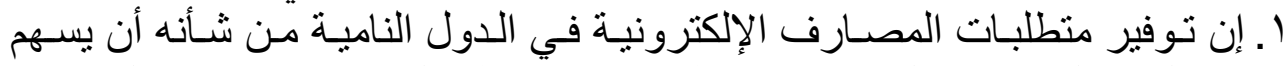

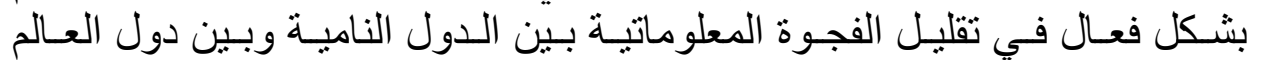
الصناعية.

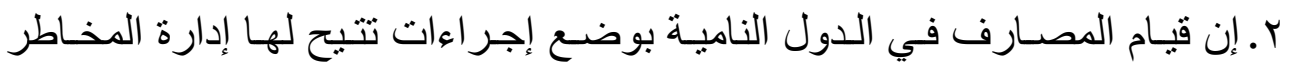

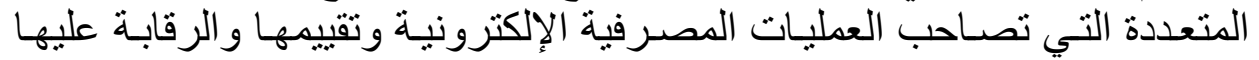

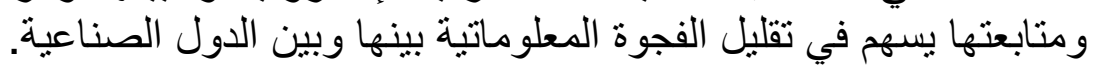

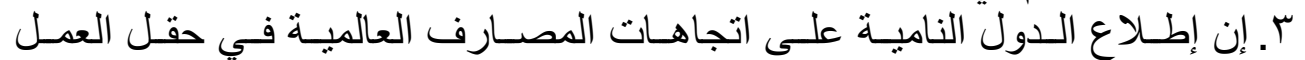

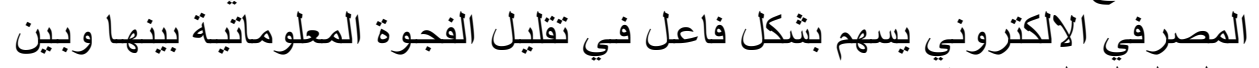
دول العالم الصناعية.

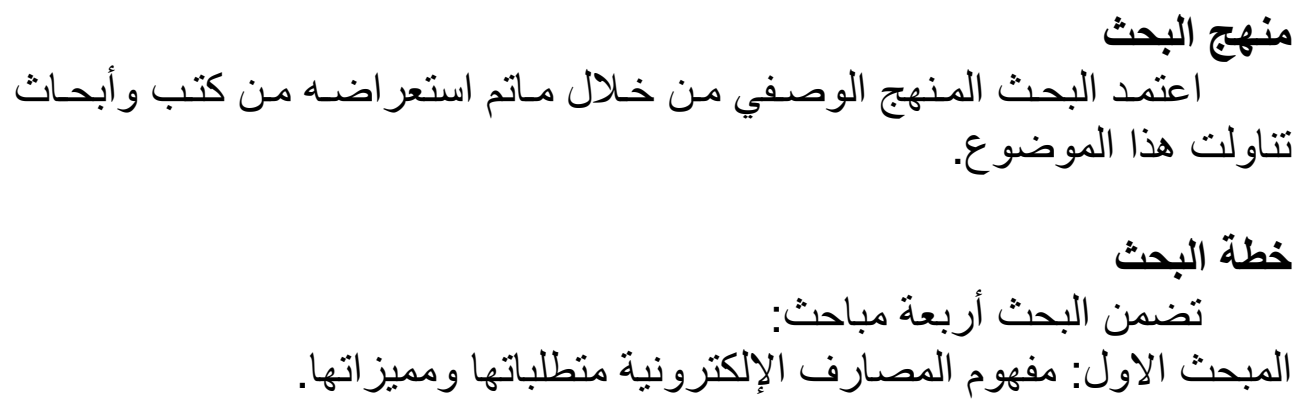


المبحـث الثـاني: مخـاطر العمليـات المصـرفية الإلكترونيـة و المبـادئ الاسترشـادية

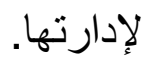

المبحث الر ابع: اتجاهـات المصـارف العالميـة في حقل العمل المصـرفي الالكتروني الإني

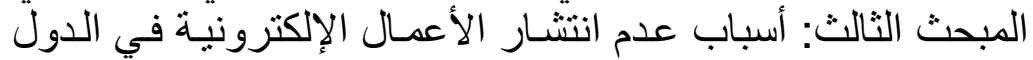

النامية وسبل معالجتها/نظرة مستقبلية.

\section{مفهوم المصارف الإكترونية: متطلباتها ومميزاتها مفهوم المصارف الإكترونية}

يستخدم إصطلاح المصـارف الإلكترونيـة (Electronic Banking) او مصـارف الانترنت (Internet Banking) تعبيراً متطوراًوشاملاً للمفاهيم التي ظهرت مع مع مطلع

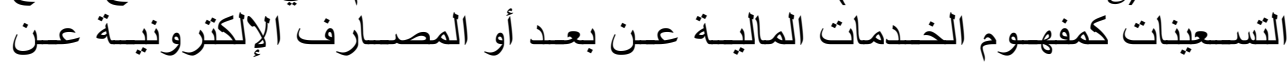

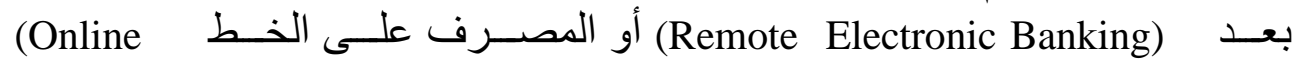
(www.arablaw.org/-Banking.htm).Banking) وجميعها تعبير ات تتصل بقيام الزبائن بإدارة حساباتهم و إنجاز أعمالهم المتصلة

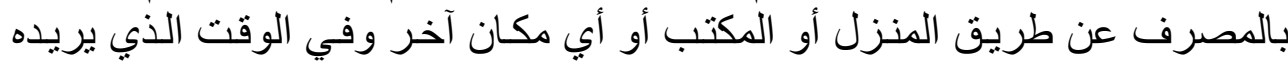

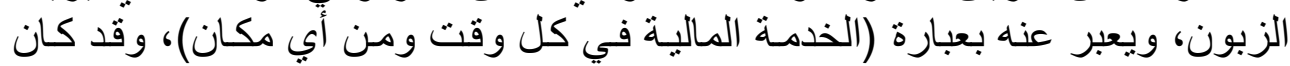

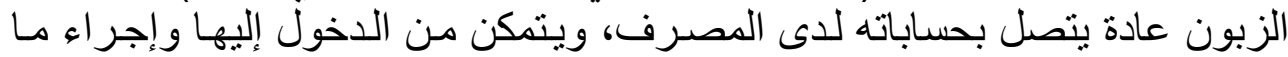

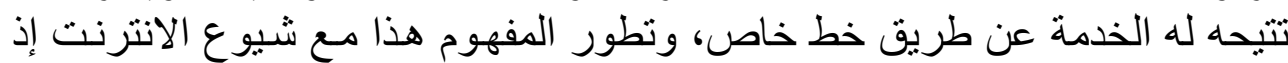

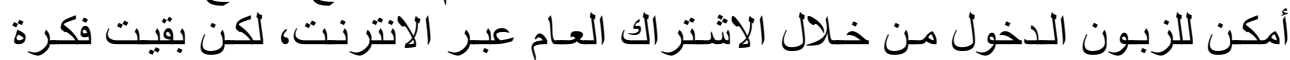

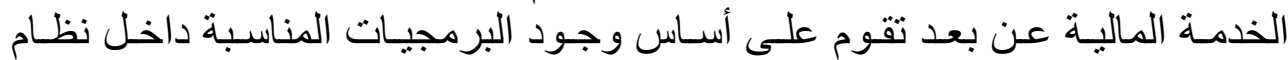

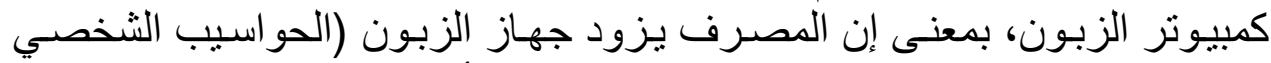
Personal Computer

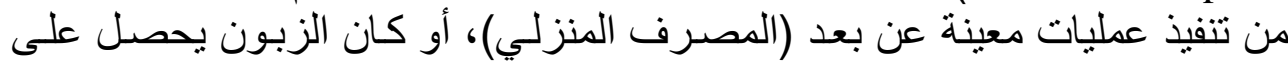

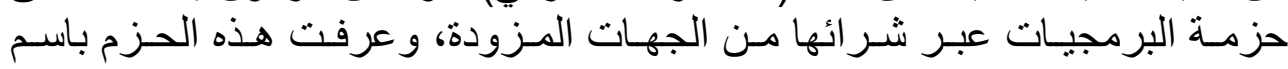

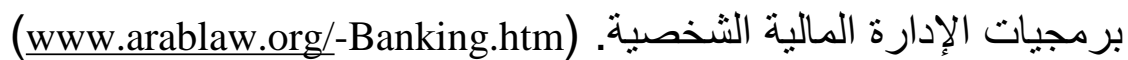

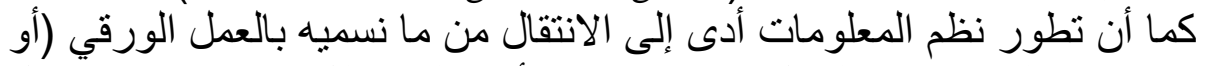

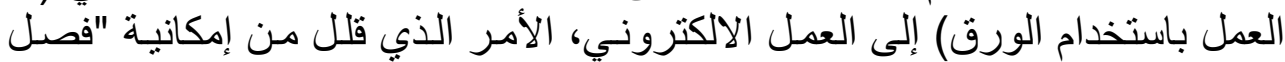

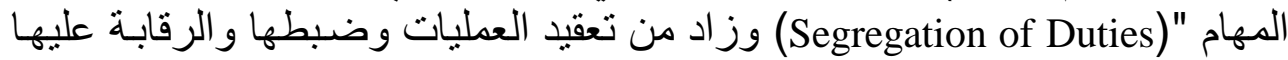

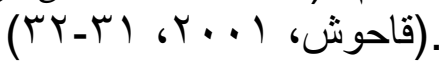

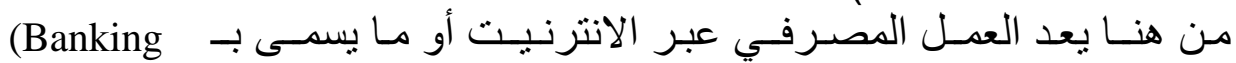

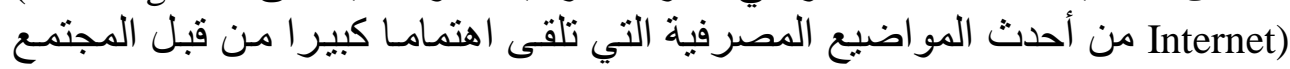

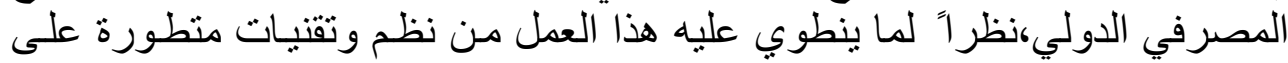

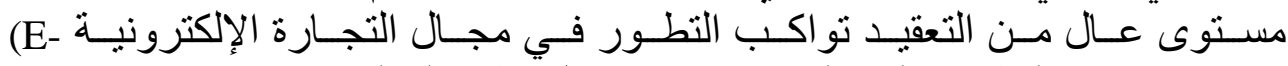

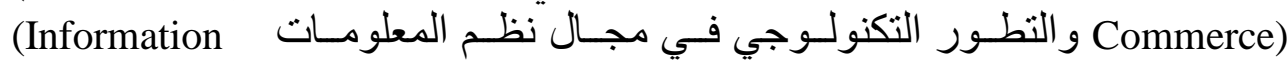

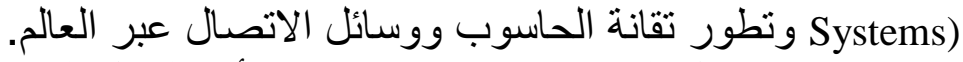

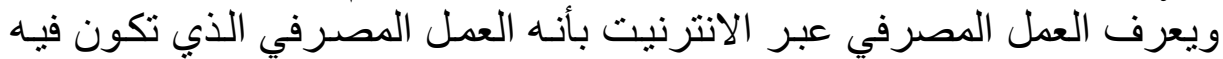

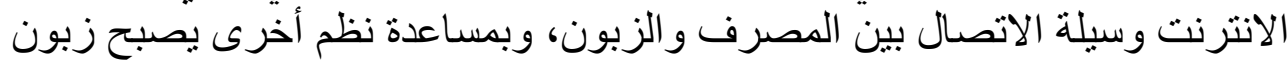


المصـرف قادراً على الاستفادة مـن الخدمات والحصـول على المنتجات المصـرفية

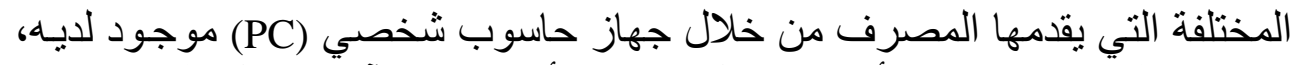

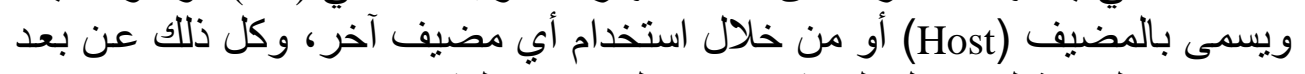

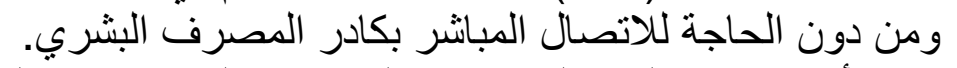

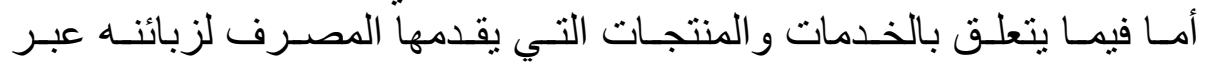

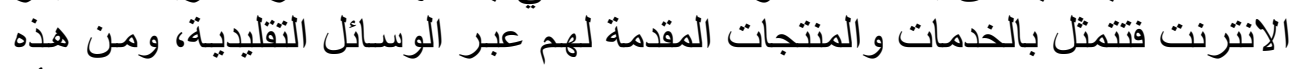

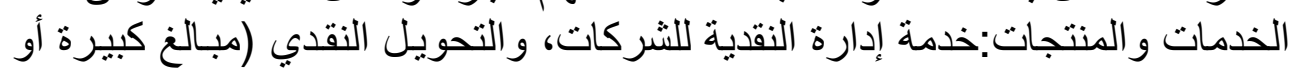

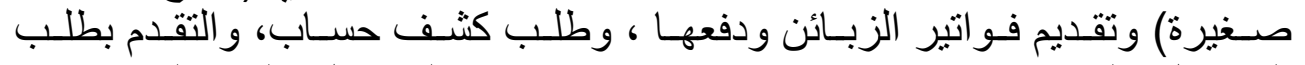

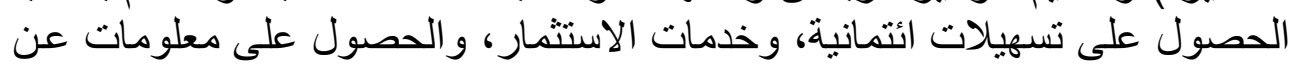

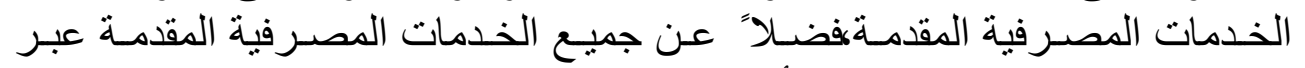

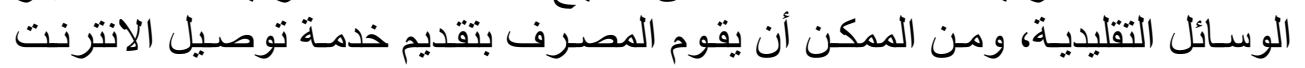

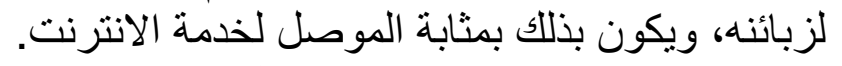

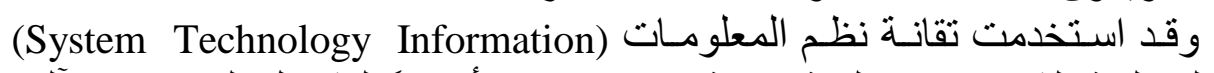

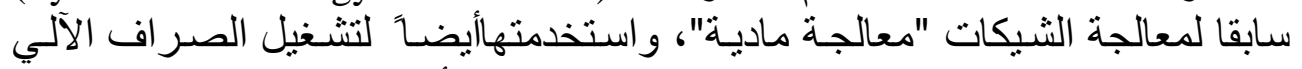

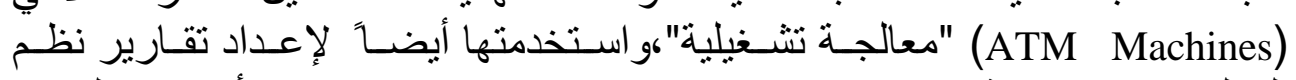

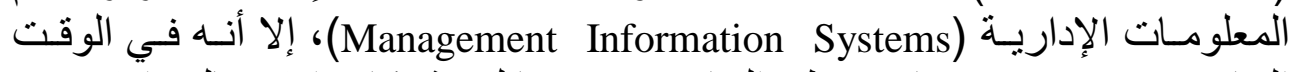

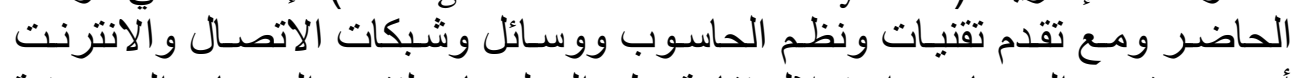

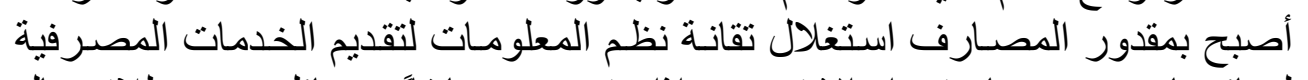

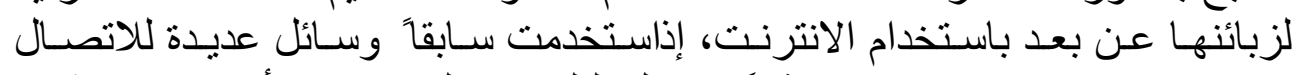

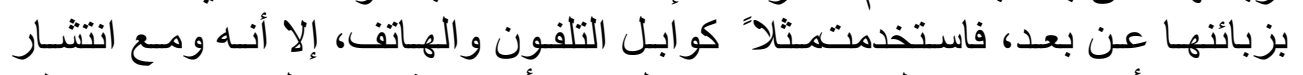

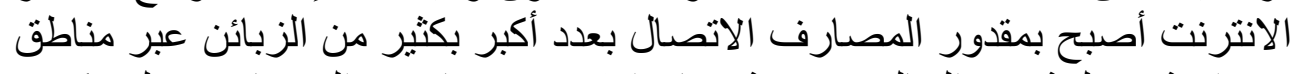

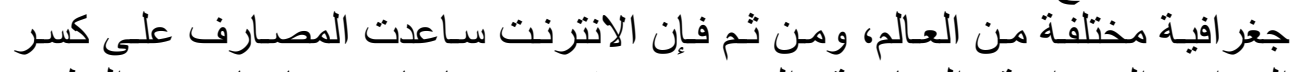

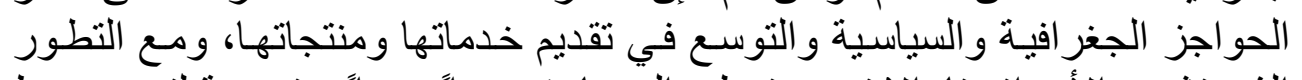

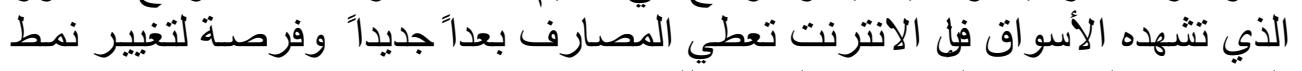

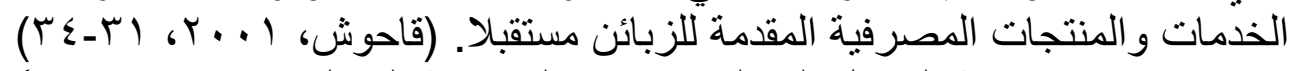

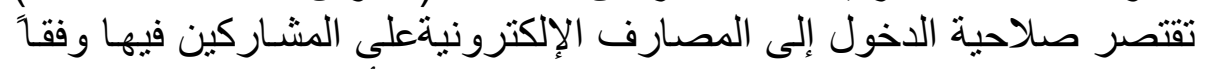

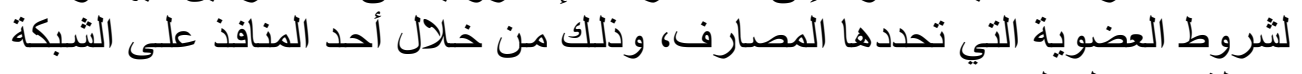

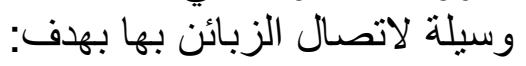

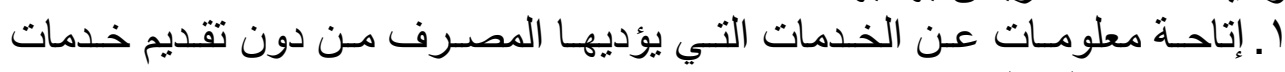
مصرفية على الثبكة

r. حصول الزبائن على خدمات محدودة كالتعرف على على معاملاتهم و أرصدة حساباتهم

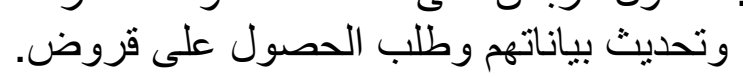

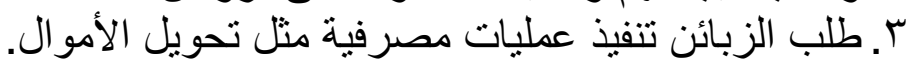

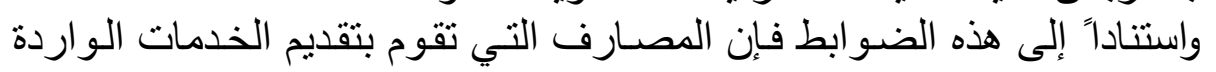

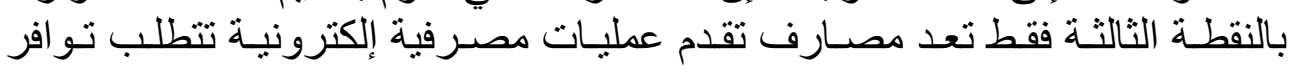
سياسات و إجر اءات لتقييم المخاطر و الرقابة علئ عليها ومتابعتها. 


\section{متطلبات المصارف الإلكترونية}

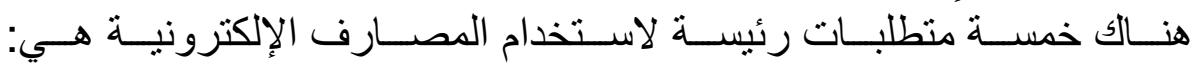

(www.arablaw.org/Download/E-Banking.doc)

أولاً -البنية التحتية التقتية

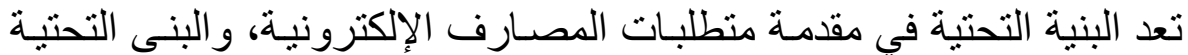

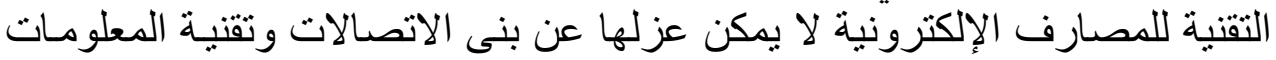

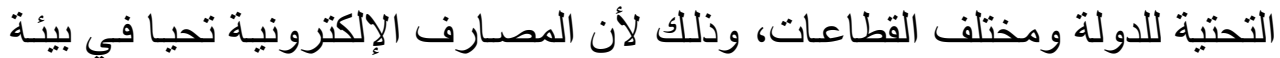

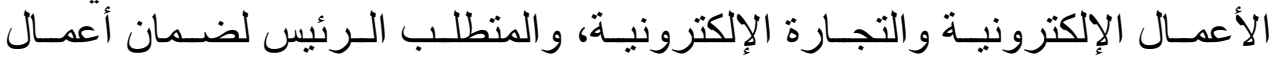

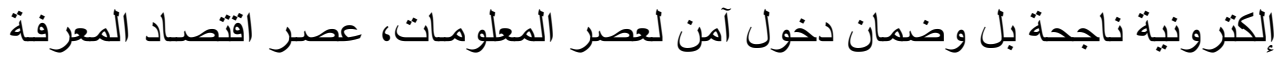

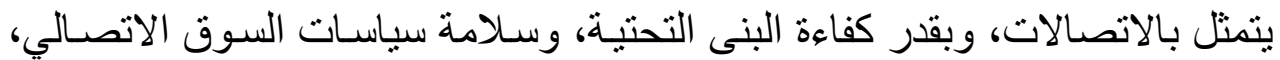

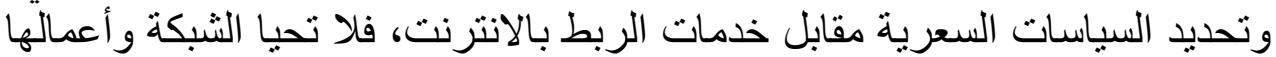

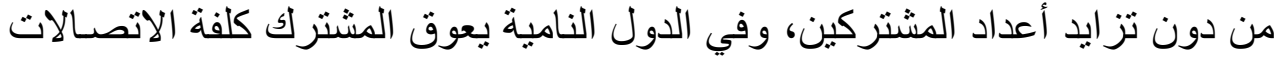

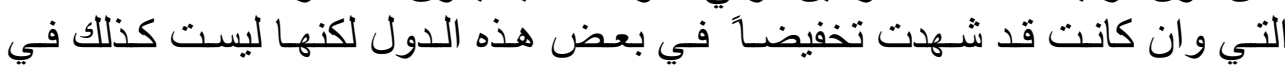

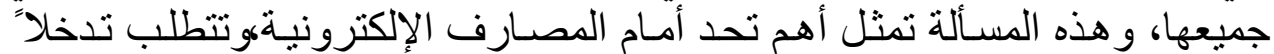

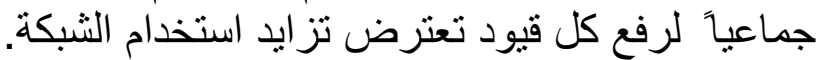
www.arablaw.org/Download/E-Banking.doc

توعمل المؤسسات المالية و المصرفية و المؤسسات المزودة لخدمة الانترنت معاح

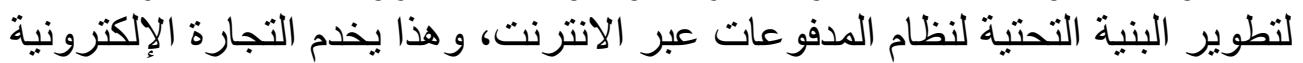

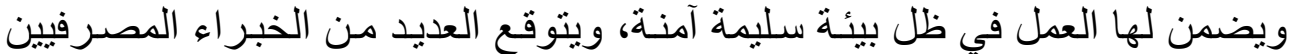

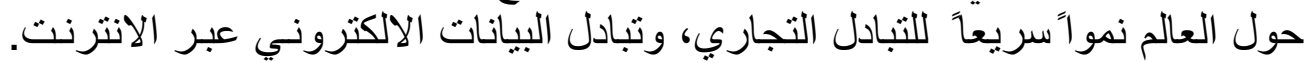

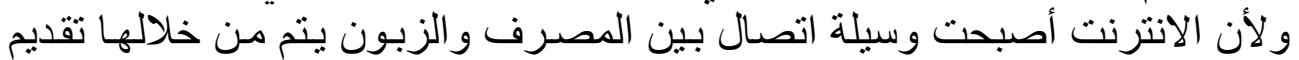

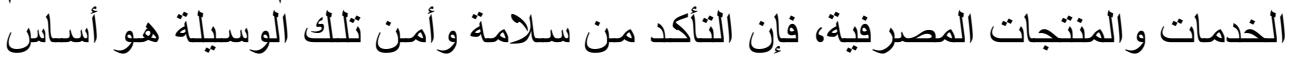

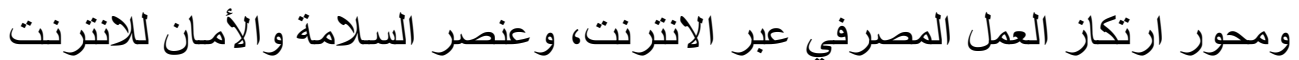

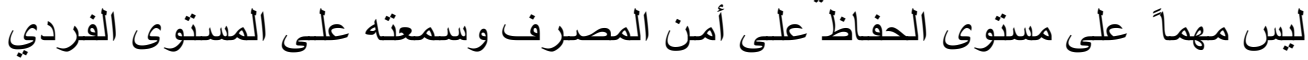

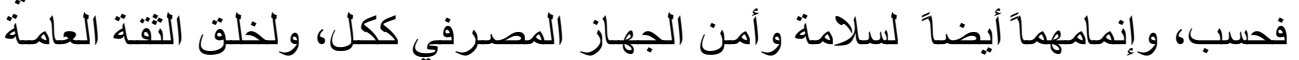

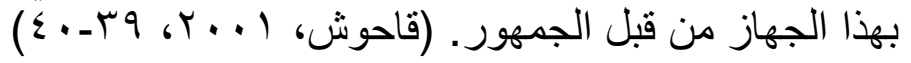

\section{ثثانياً ـ- الكفاءة الأدائية المتفقة مع عصر التقتية}

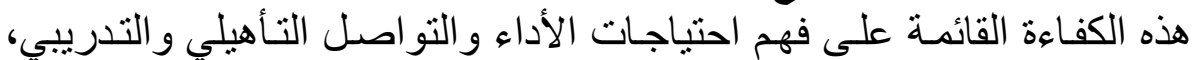

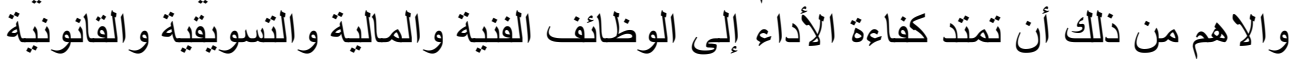
و الاستشارية و الإدارية المتصلة بالنشاط المصنية الأدرفي الالكتروني.

\section{ثالثاً ـ التطوير والاستمرارية والتفاعلية من المستجدات}

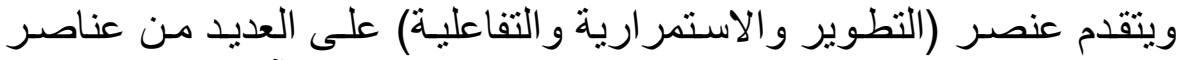
متطلبات بناء المصارف الإلكترونية وتميز ها، فالجمود و انتظـار الآخرين لايتفق مـع 


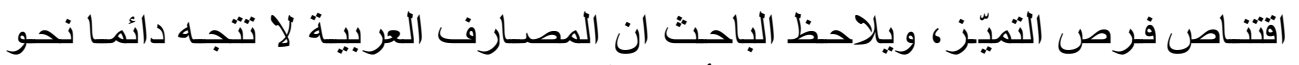

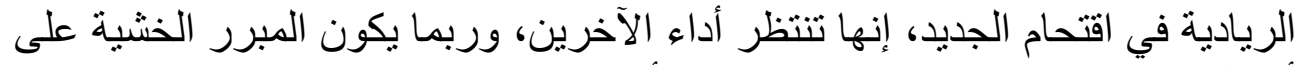

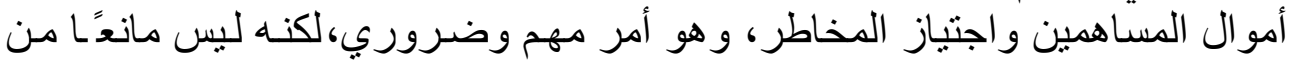

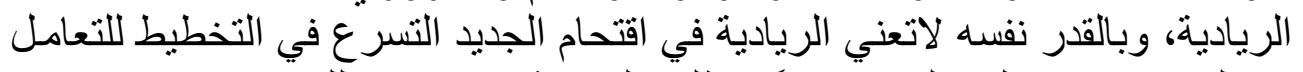

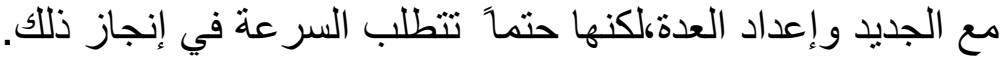

رابعاً ـ التفاعل مع متفيرات الوسائل والاستراتيجيات الفنية والإدارية والمالية

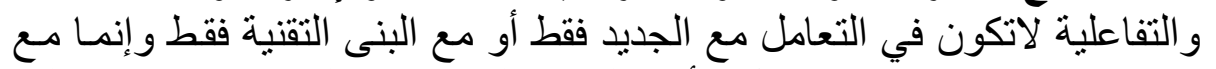

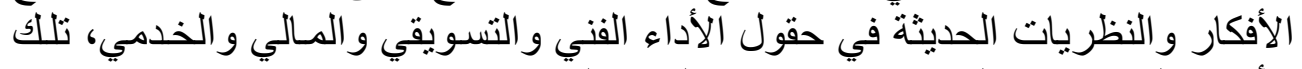
الأفكار التي تكون وليدة تفكير إبداعي وليس وليد اليدي تفكير نمطي.

خامساً - الرقابة التقييمية الحيادية إن واحداً من عناصر النجاح هو الرية الركون إلى القادية القادين على التقييم الموضوعي،

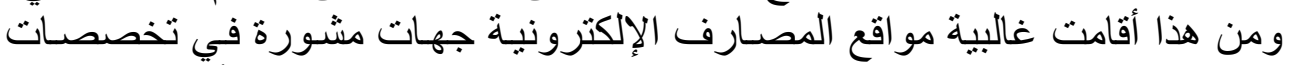

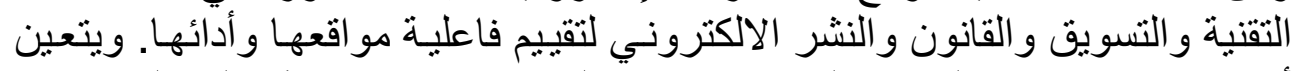

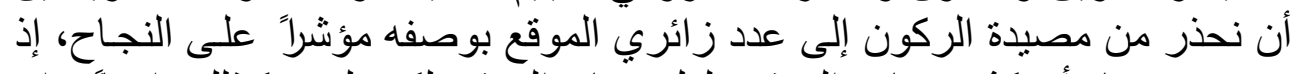

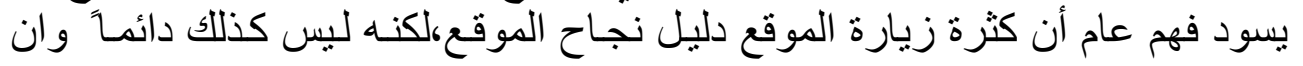

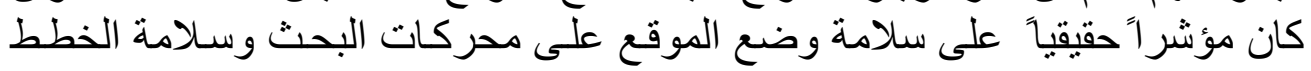

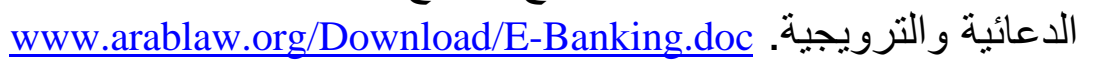

\section{مميزات المصارف الإلكترونية}

يتميز نظام الصيرفة عبر الإكترونية الانترنت بعدة مز ايا منها:

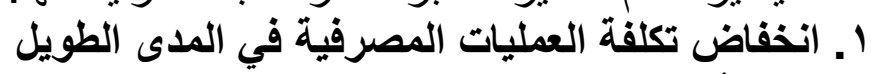

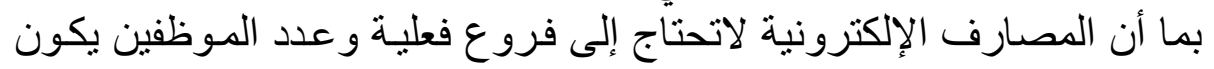

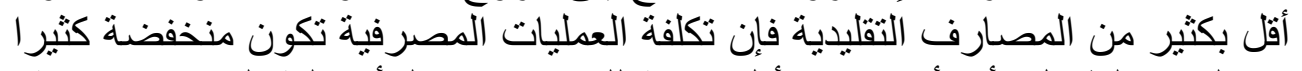

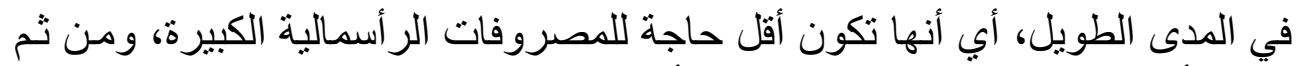

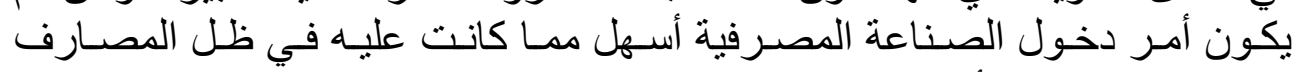

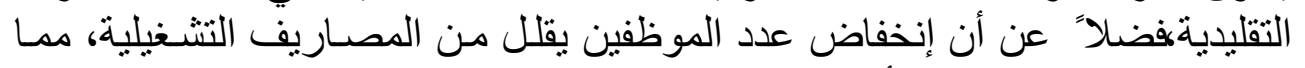

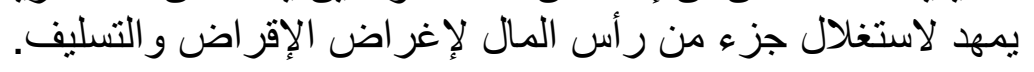

\section{r. سهولة المقارنة والتحليل}

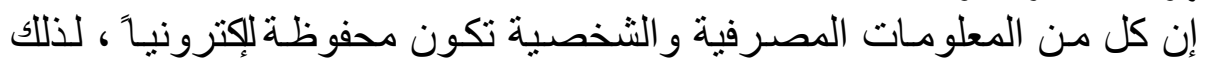

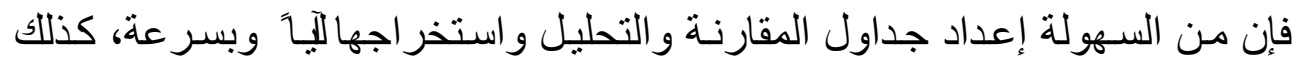

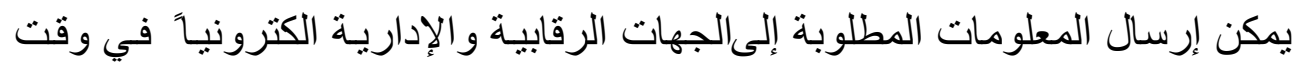




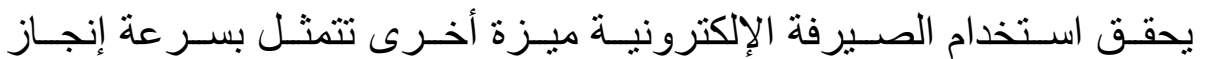

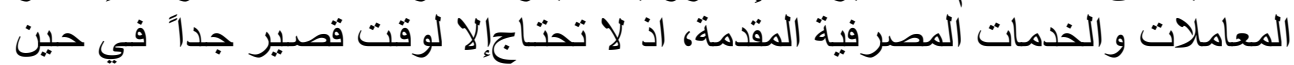

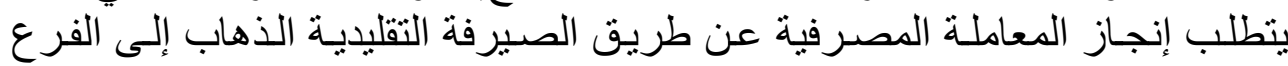
المصرفي و الانتظار لحين انتهاء المعاملة.

ع ـسهولة إعادة هيكلة الأعمال المصرفية

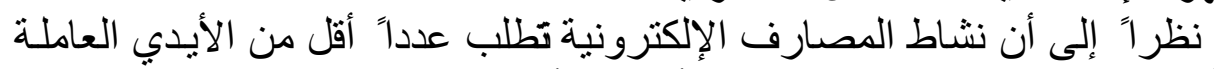

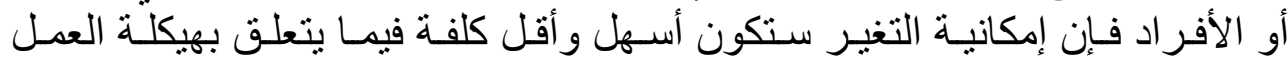
المصرفي.

•ـ القدرة على تسويق المنتجات المصرفية خارج حدود الدولة ألام

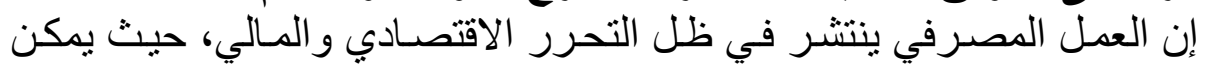

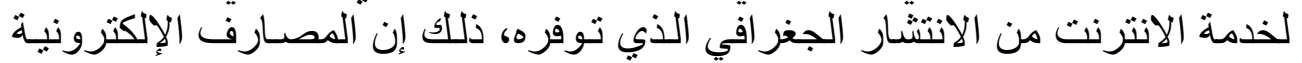
تتجاوز الحدود الجغر افية ويمكن تسويق المنتجات الاتي في أي دولة أخرى.

7 . خيارات أكثر بالنسبة للزبائن

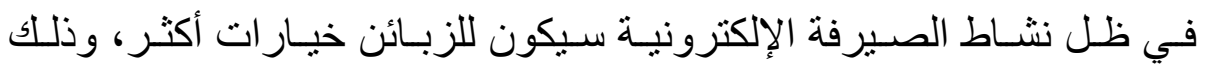

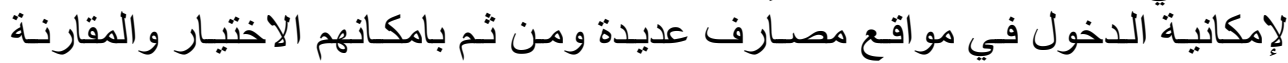

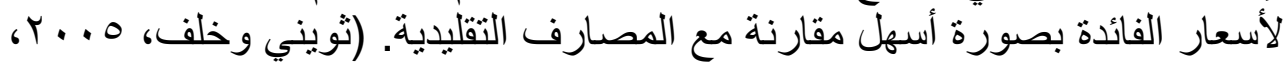

هذلفضلاً عن المميز ات المتعددة للعمليـات المصرفية الإلكترونيـة ومنهـا مـا يأتي: (www.cbe.org.eg/public/regulations\%20of\%20the\%20Electronic\%20Bank ing\%20operations.doc)

ا. . إمكان وصول المصارف إلى قاعدة أعرض من الزبائن المودعين و المقترضين

$$
\text { وطالبي الخدمات المصرفية المدية. }
$$

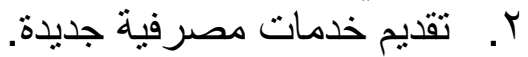

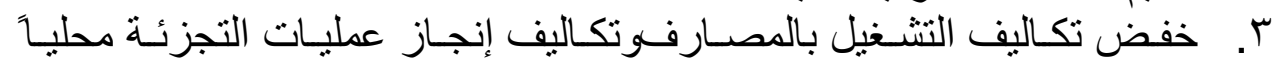

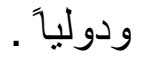

ع. ـ زيادة كفاءة أداء المصارف.

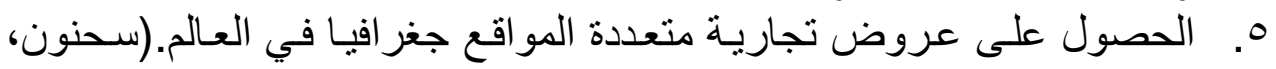

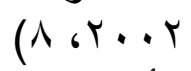

7. تأمين المبالغ النقدية من الضياع و السرقة.

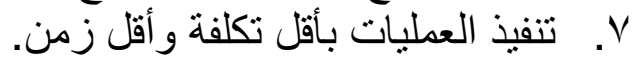

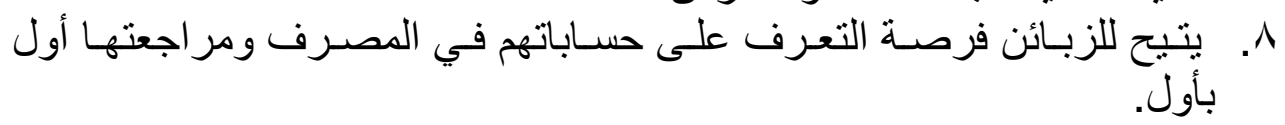




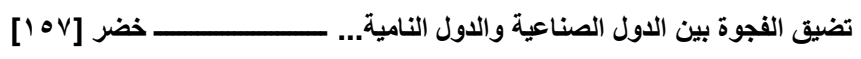

9 . . يتيح فرصة للزبائن للقيام بعملية تحويل الأمو ال للداخل والخـارج ودفع أثمان

السلع وتحريك رأس المال وتوجيهه نحو المجات بعالات الاستثمارية المختلفة.

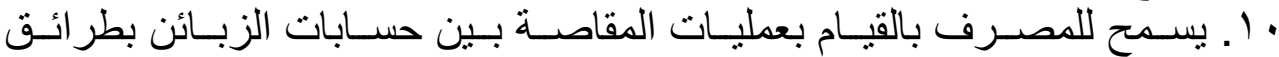

الإلكترونية.

أما مشاكل العمليات المصرفية المية الإلكترونية، فتمثنل في:

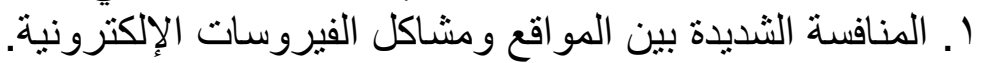

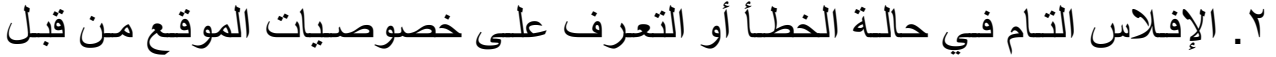

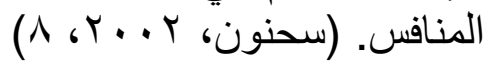

\section{مخاطر العمليات المصرفية الإلكترونية والمبادئ الاسترشادية لإدارتها مخاطر العمليات المصرفية الإكترونية}

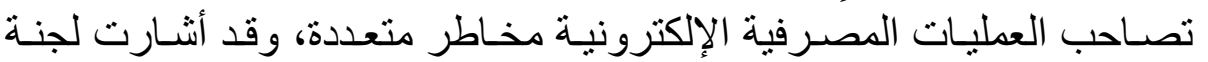

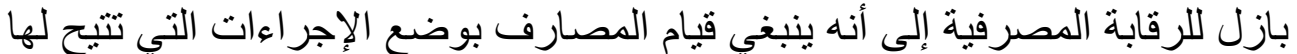

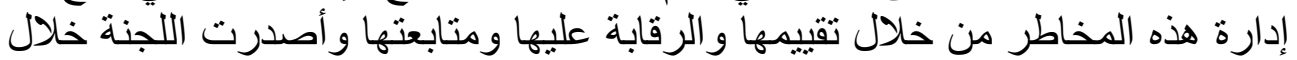

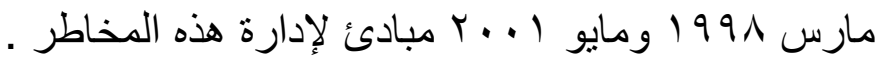

(www.cbe.org.eg/public/regulations\%20of\%20the\%20Electronic\%20Banki ng\%20operations.doc)

$$
\text { ومن أنواع هذه المخاطر مايأتي: }
$$

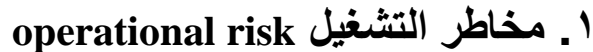

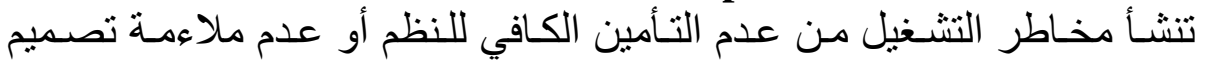
النظم أو إنجاز العمل او أعمال الصيانة وكذا نتيجة إسـاءة الاستخدام من قبـ التبل الزبائن وذللك على النحو الآتي :

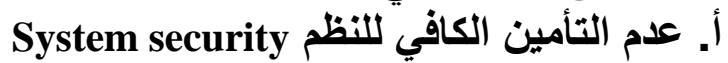

تنشأ هذه المخاطر عند اختراق غير المرخص لهم لنظم حسـابات المصرف

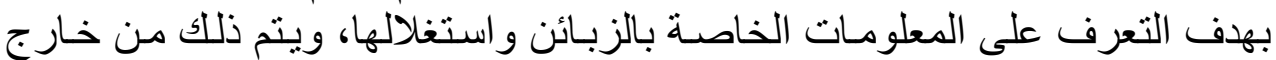

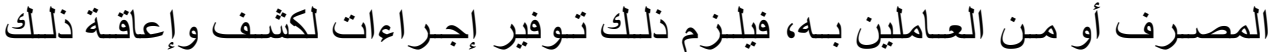

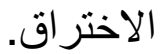

ب. عدم ملاعمة تصميم النظم أو إنجاز العمل أو أعمال الصيانة Systems design, implementation, and maintenance

و هي تنشـأ من إخفاق النظم أو عدم كفاءتها (بطء الأداء على سبيل المثنال)

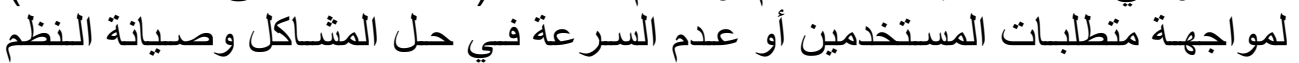
و الحاجة إلى الاعتماد على مصادر خارج المصسارف لتقديم الداعم الفني بشـأن البنيـة

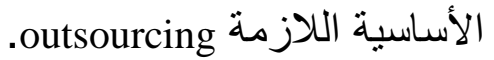

ج. إساءة الاستخدام من قبل الزبائن Customer misuse of services 


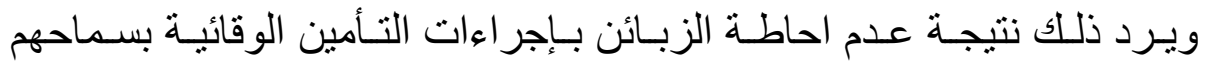

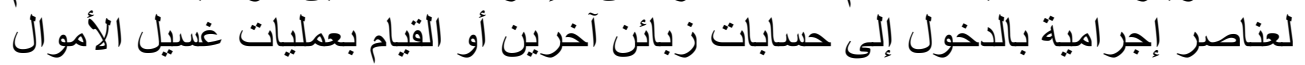

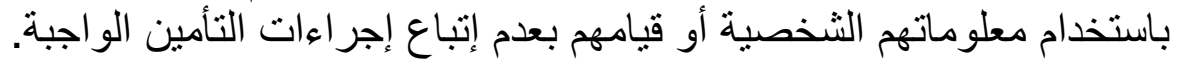

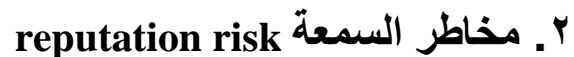

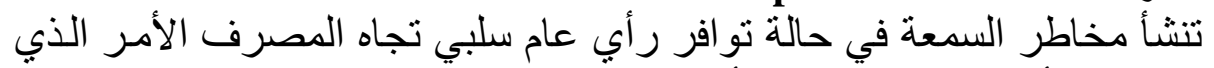

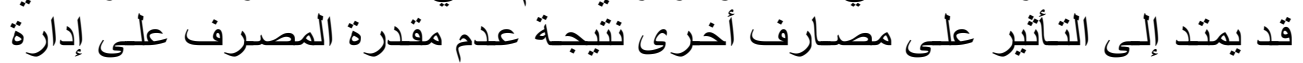

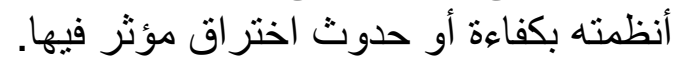

\section{regal risk المخاطر القانونية}

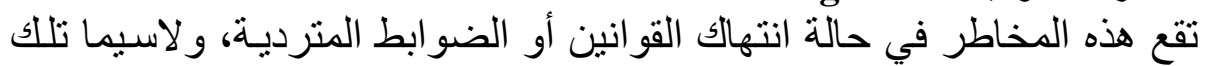

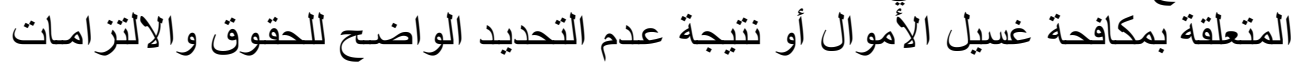

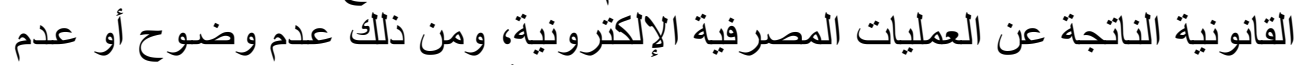

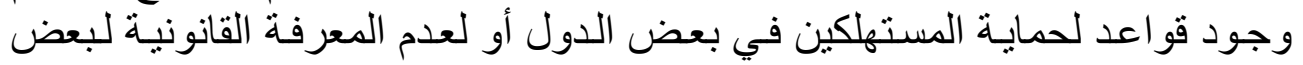

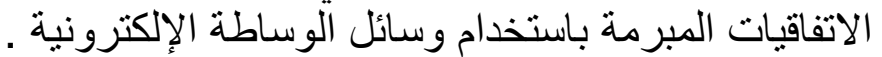
(www.cbe.org.eg/public/regulations\%20of\%20the\%20Electronic\%20Banki ng\%20operations.doc)

عندما تكون المؤسسة المصرفية ذات وجود فاعل على شبكة الانترنت، يعني المني

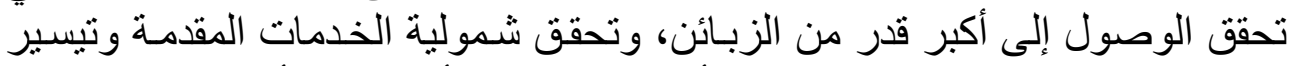

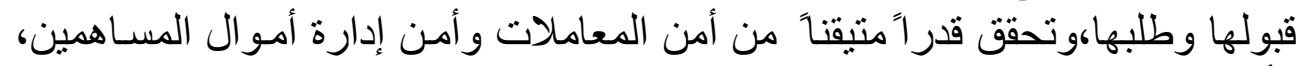

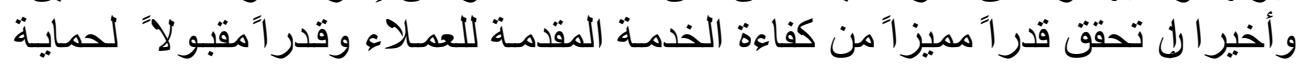

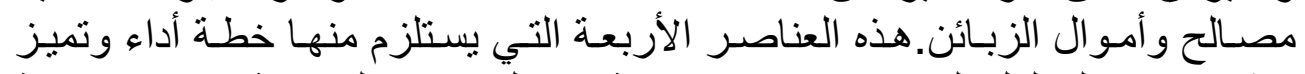

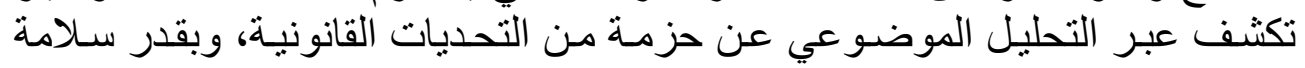

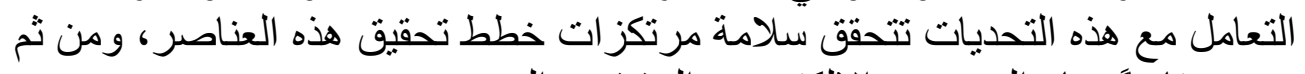

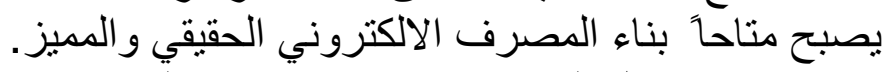

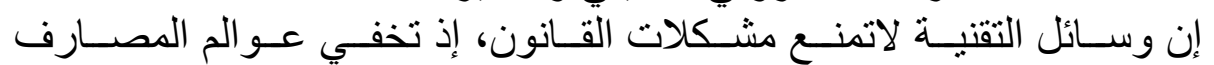

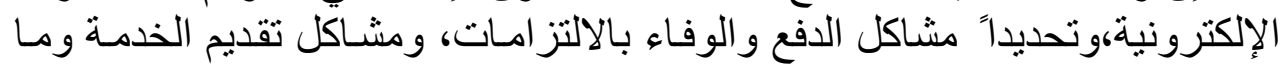

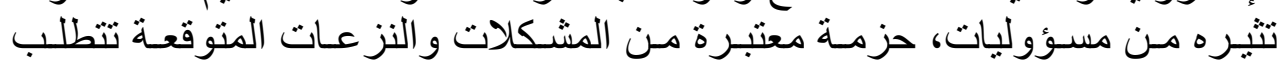

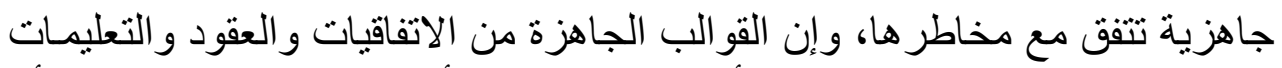

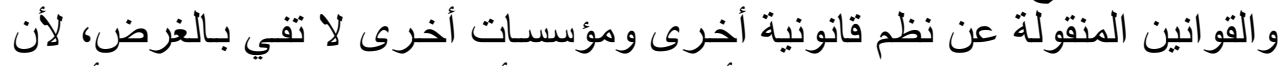

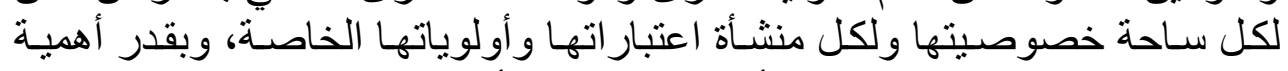
الإطلاع على تجارب الغير فإن الأهمية تكمن بقدر أكبر في فهم الاحتياجات الأنات الداخلية

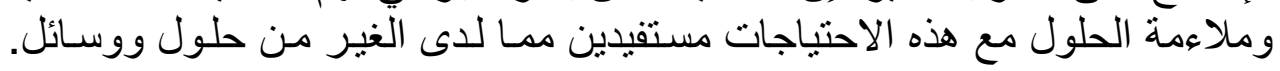

(www.arablaw.org/Download/E-Banking.doc)

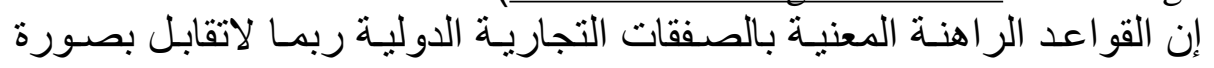

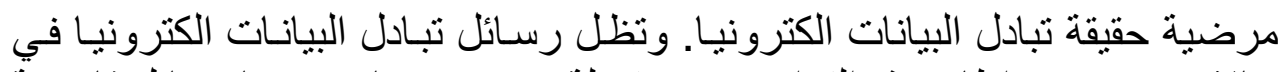

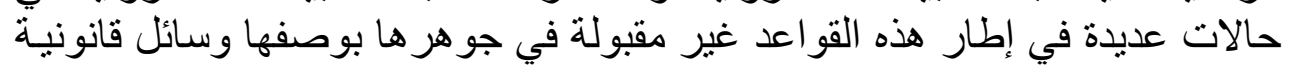




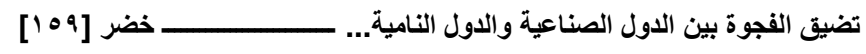

للإبـلاغ. وينظر إلى الاحتياجـات القائمـة، في إطـار قو انين وطنيـة واتفاقـات دوليـة

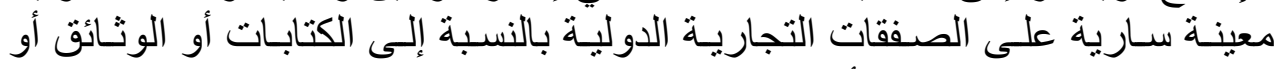

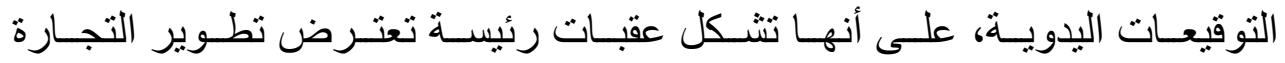

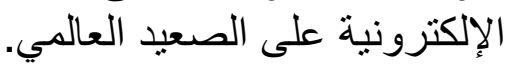

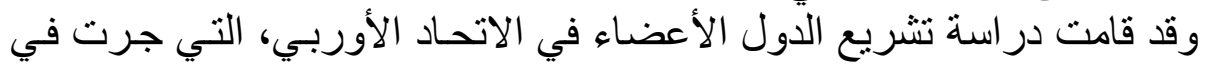

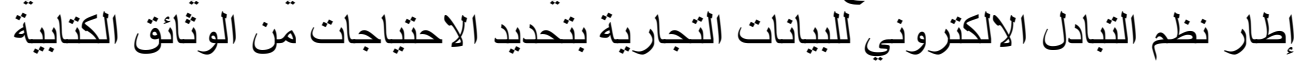

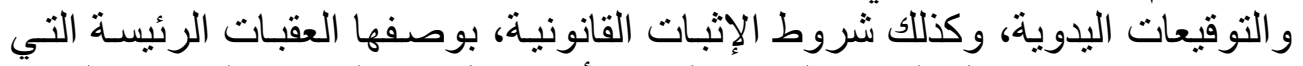

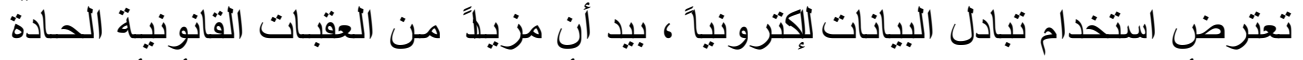

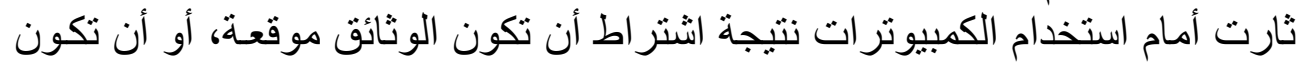

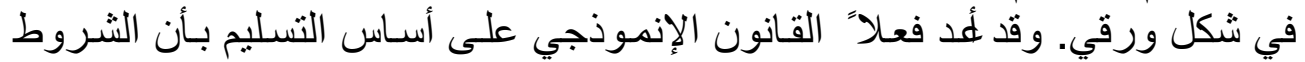

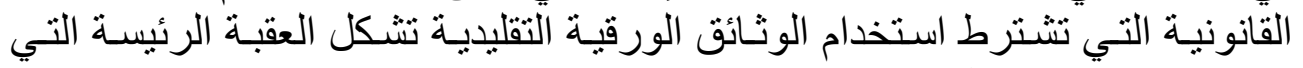

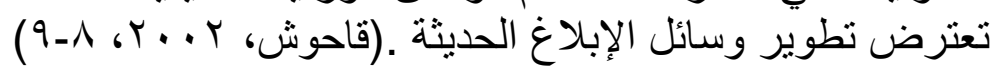

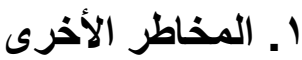

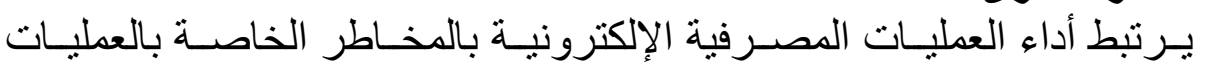

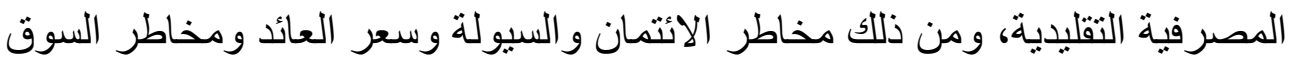

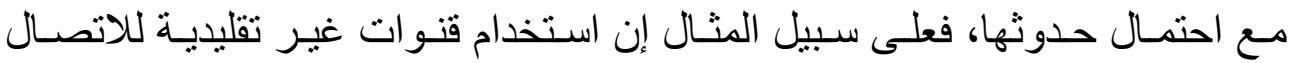

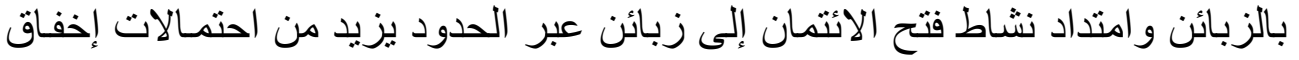

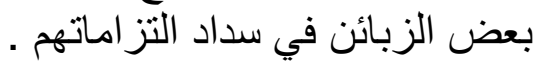

(www.cbe.org.eg/public/regulations\%20of\%20the\%20Electronic\%20Banki ng\%20operations.doc)

ويرى الباحث أنه لابد من الإشارة إلى التحديات الضريبية والجمركية للتجـارة

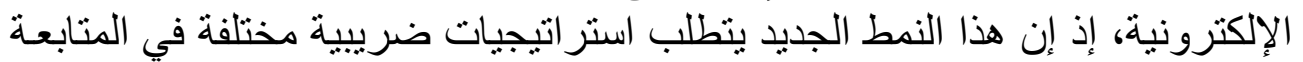
و الكثف و الجمع، لما تثيره قو اعد محاسبتها و التعرف على على حقائق الدخل المتأتي منها

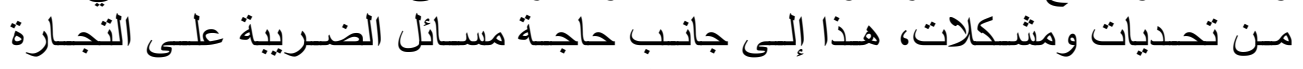
الإلكثرونية إلى تعاون وتنسيق إقليمي ودولي.

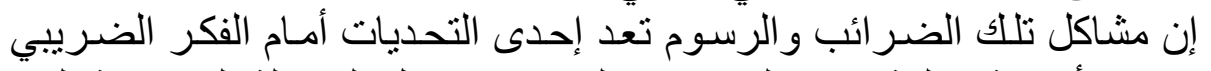

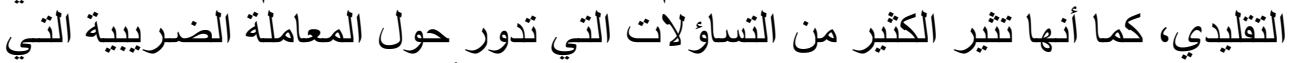

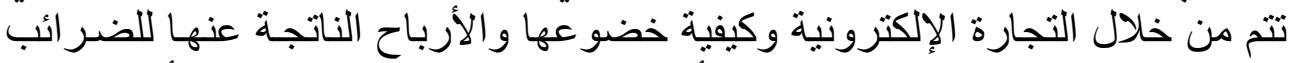

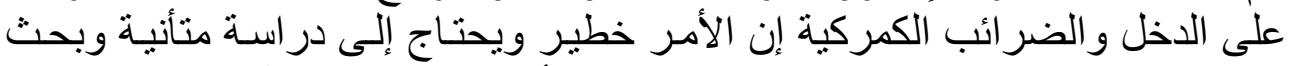

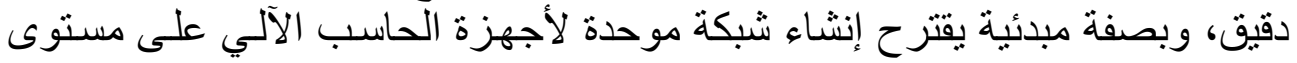

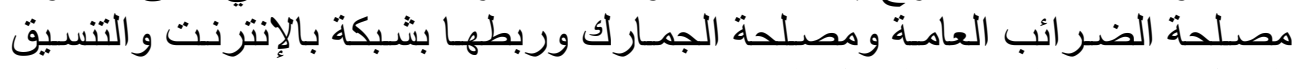

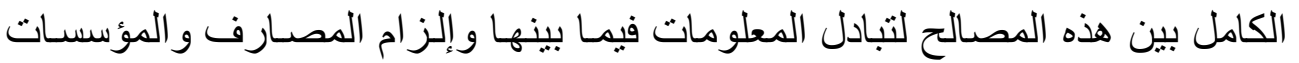

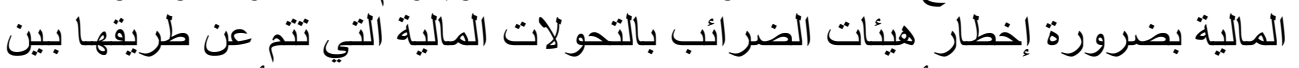
المشروعات سو اء كان أطر اف هذه التحويلات مقيمين داخل الدولة الته أو خارجها.

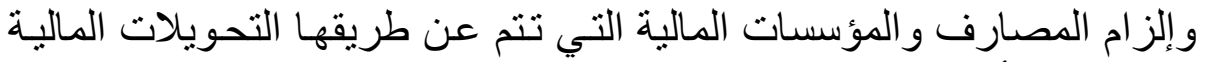

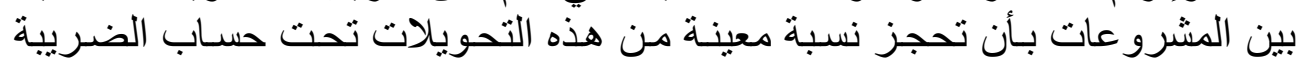

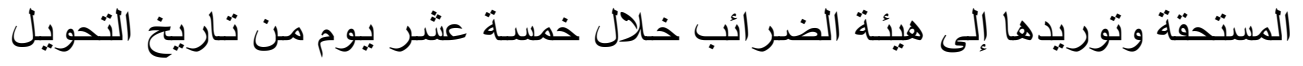


بحيث يجب أن يقترن السـاد بتقديم بيـان موقع عليهه من البنلك او المؤسسـة المالية يوضح نوع كل من هذه التحويلات.

المبادئ الاسترشادية للمصرف لاى تقديم خدماته عبر شبكات الاتصال الإلكترونية

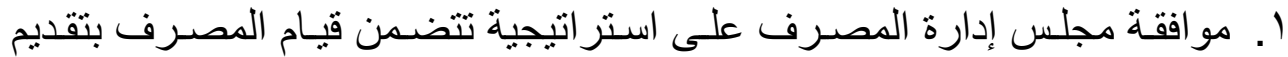

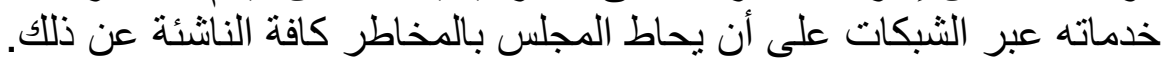

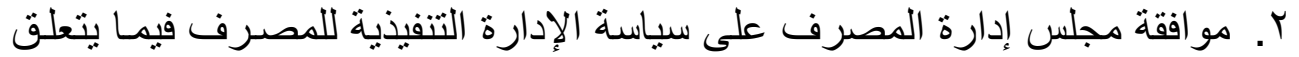

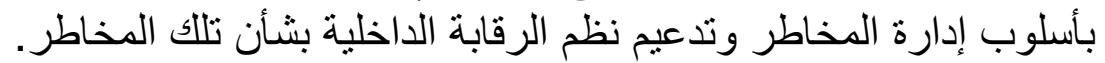

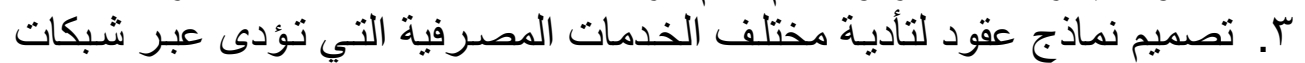

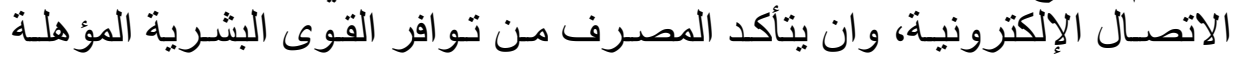

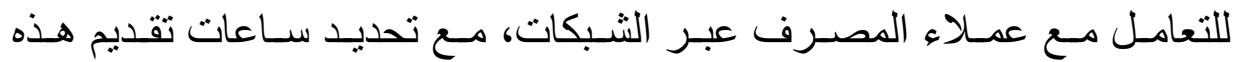
الخدمات.

ع. في حالـة وجـود طرف آخـر تقدم مـن خلالـه الخدمـة يتعين على مجلس ادارة

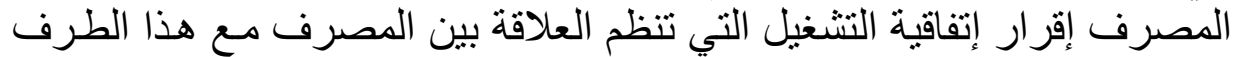

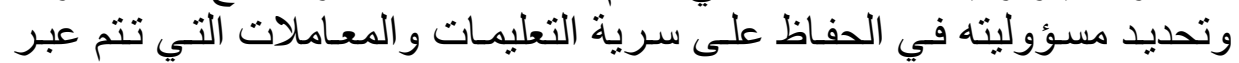

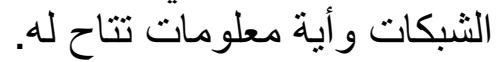

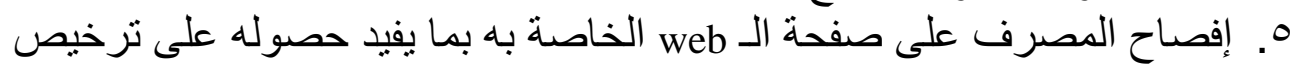

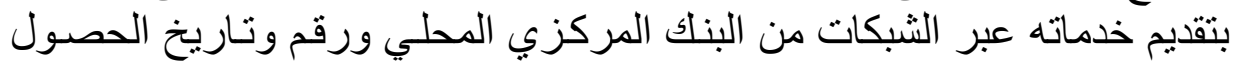

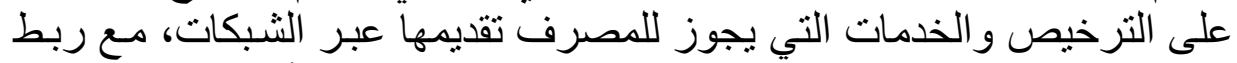

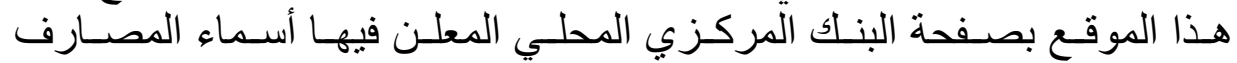

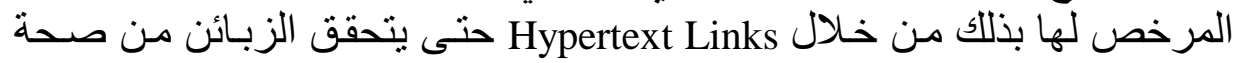
التصريح. 7. إفصـاح المصرفرف عن أن القوانين المحلية هي التي تحكم الخدمات التي يقوم

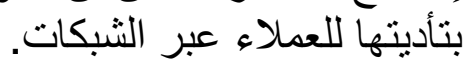
V. ضرورة أن يتحقق المصرف من شخصية طالب/متلقي الخدمـة بأسـاليب قانونية ثابتة تضمن الحقوق المتبادلة. (www.cbe.org.eg/public/regulations\%20of\%20the\%20Electronic\%20Banki ng\%20operations.doc)

\section{اتجاهات المصارف العالمية في حقل العمل المصرفي الاكتروني}

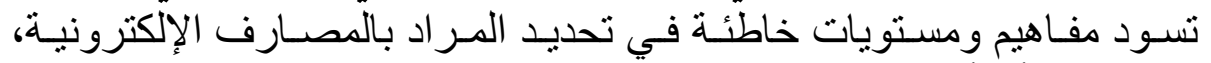

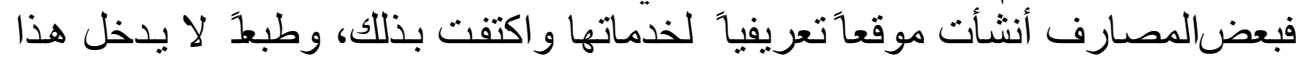

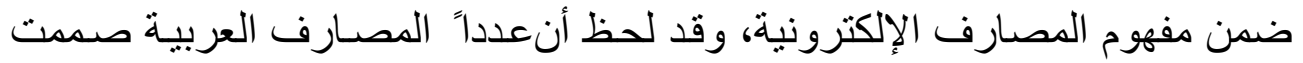

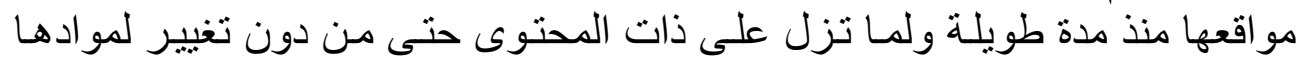

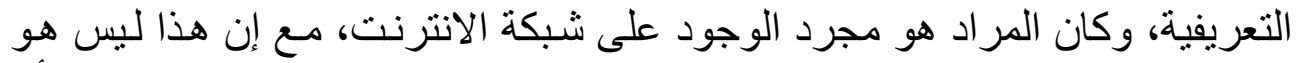

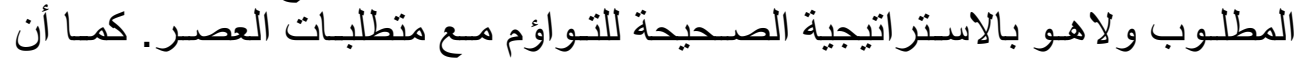

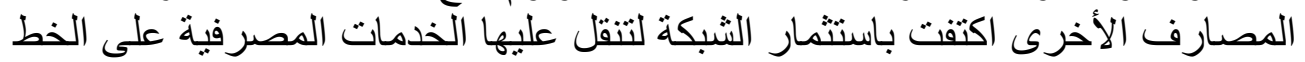




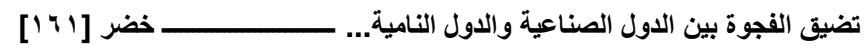

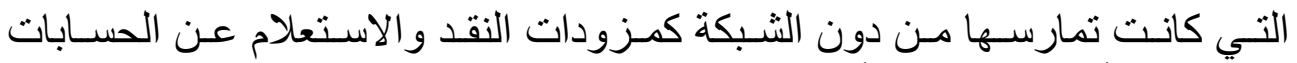

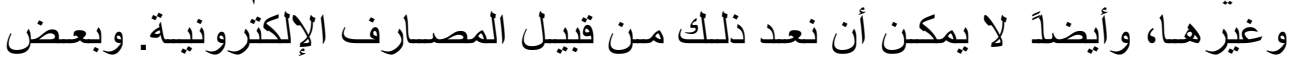

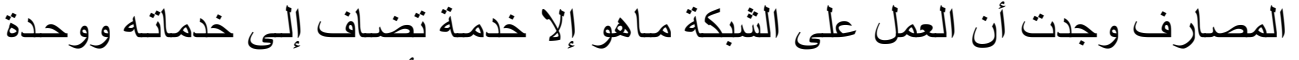

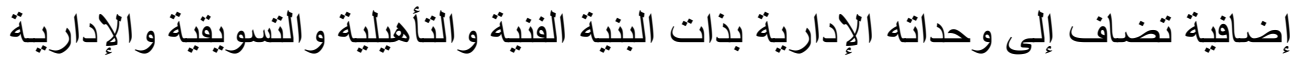

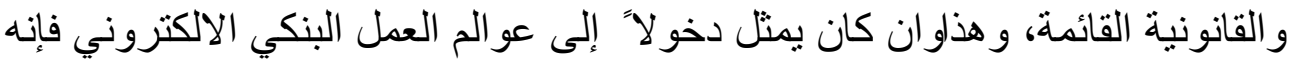

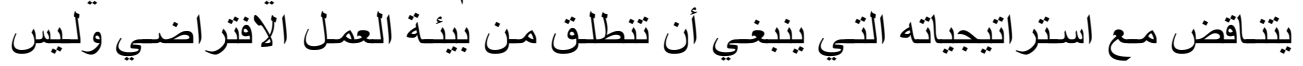

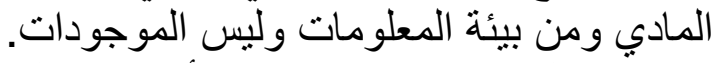

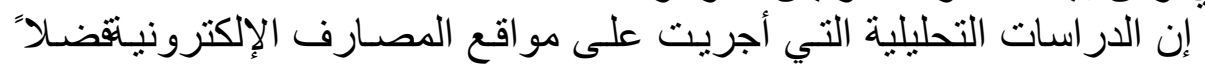

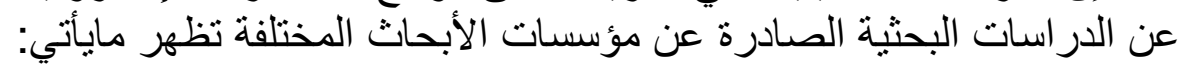

() www.arablaw.org/Download/E-Banking.doc ا. . غالبية مو اقع المصارف على الانترنت مواقع تعريفيـة معلوماتيـة وليست مواقع خدمات مصر فية على الخط الخط.

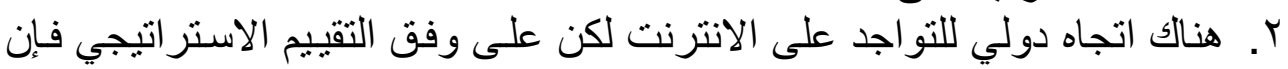

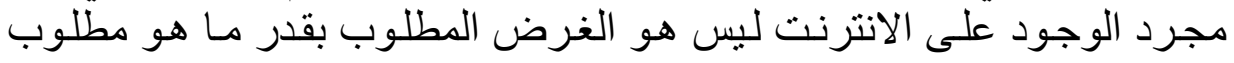

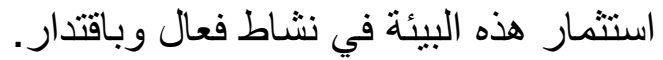

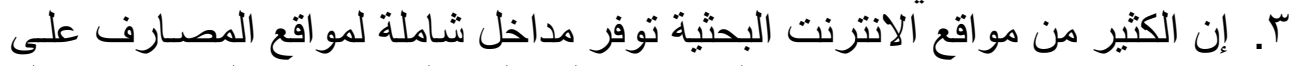

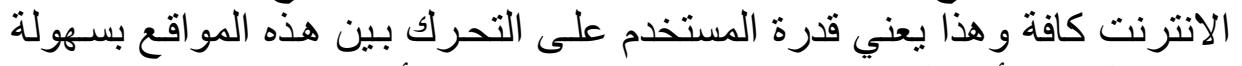

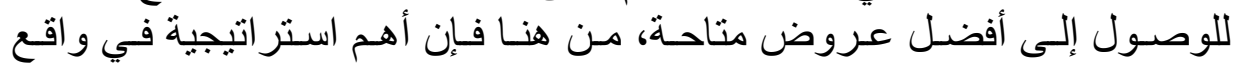

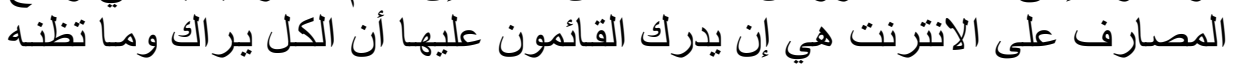

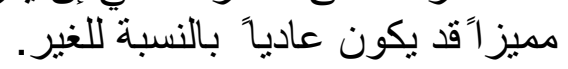

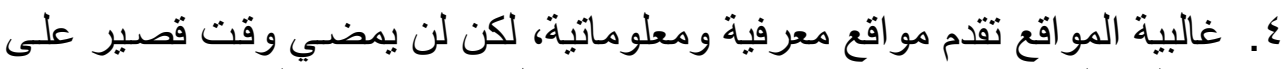

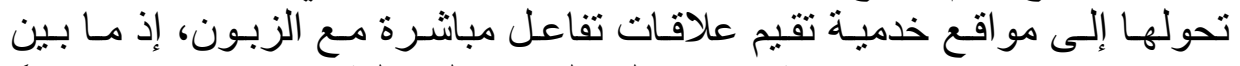

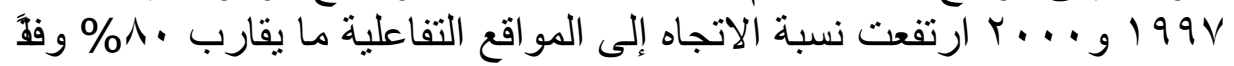
للار اسات.

\section{أسباب عدم انتثار الأعمال الإكترونية في الدول النامية وسبل معالجتها- نظرة مستقبلية الإنية \\ أسباب عدم انتثار الأعمال الإكترونية في الدول النامية الألية}

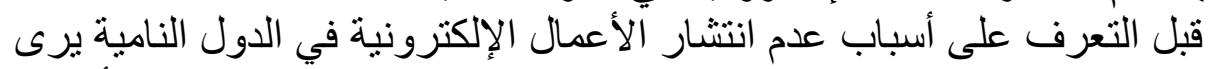

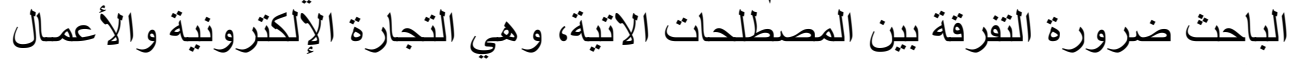

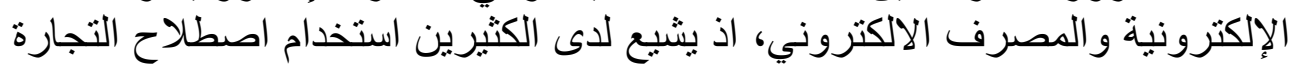

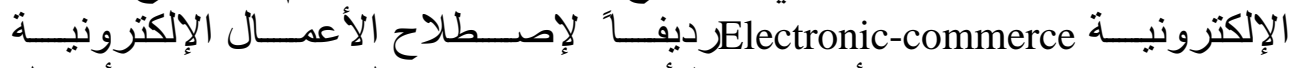
Electronic-business

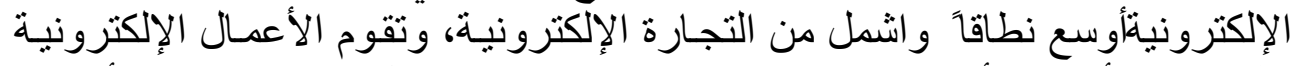

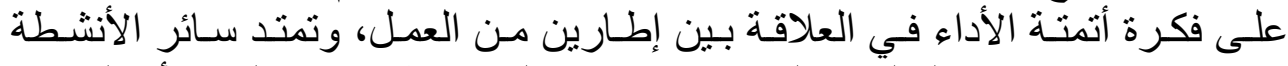

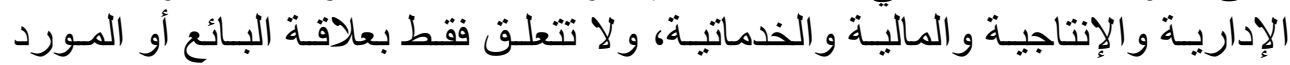

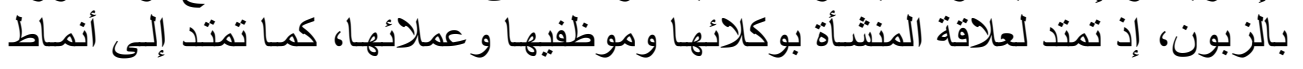




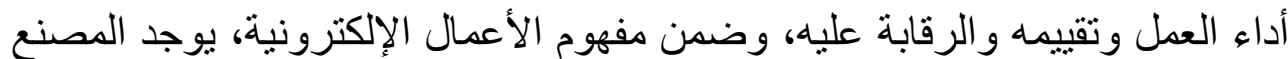

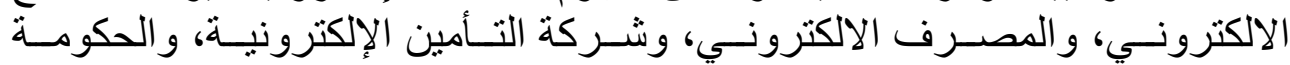

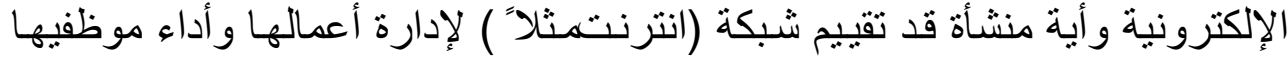

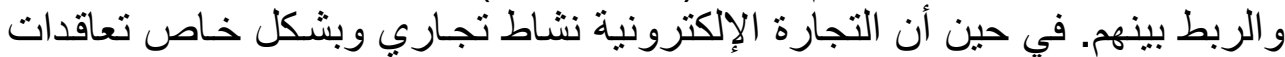

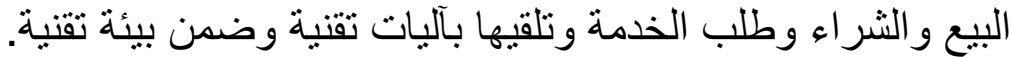

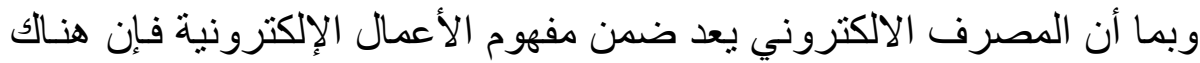

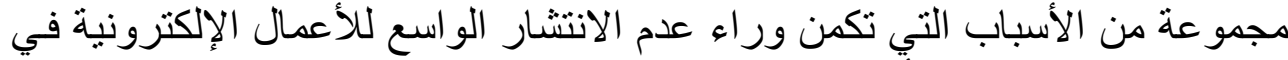

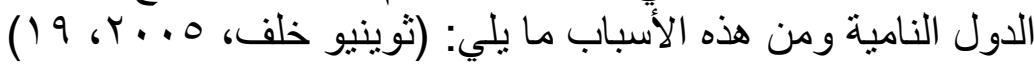

أولاً - عدم توافر البنية التحتية الكافية للأعمال الإكترونية، إذ لا يوجد بيئة مناسبة

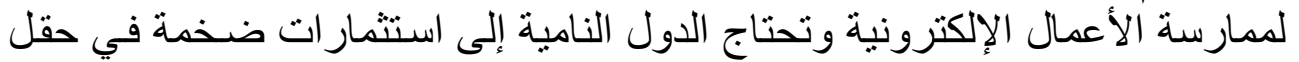
الانترنت حتى تهيئ البنية القادرة على تحمل أعباء ومخاطر الأعمال الإلكترونية.

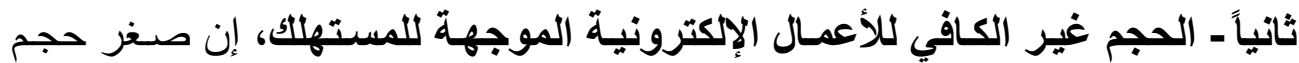

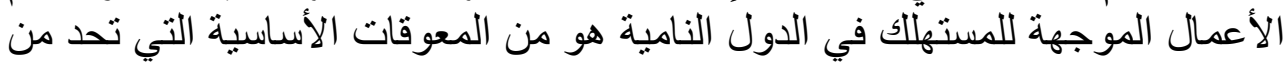

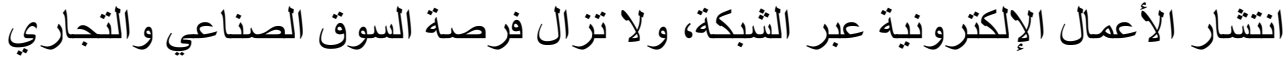

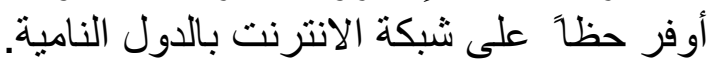

ثالثاً ـ عدم توافر بنية تحتية كافية للخدمات المالية، حتى تتجح الأعمال الإلكترونية

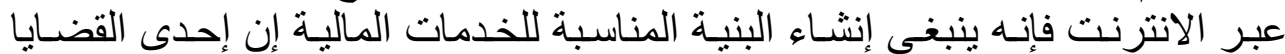

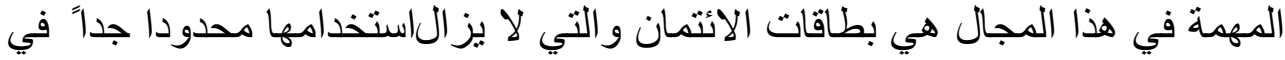
الدول النامية.

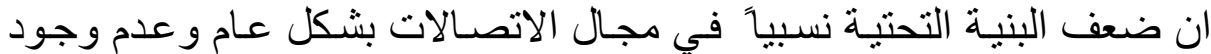

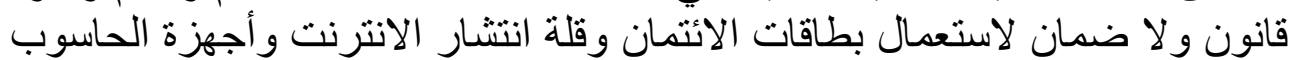

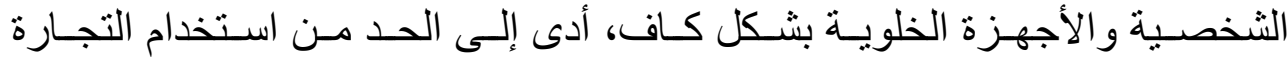
الإلكترونية على نطاق واسع في عمليات المتاجرة.

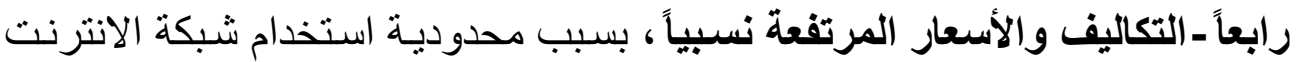
فإنه لاتز التكاليف الإنشاء وأسعار الاستضافة مرتفعة نسبياً مقارنـة بالدول المتقدمة الإنة

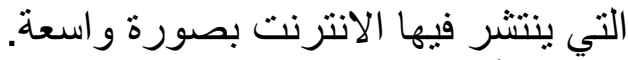

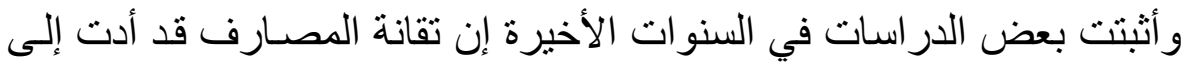

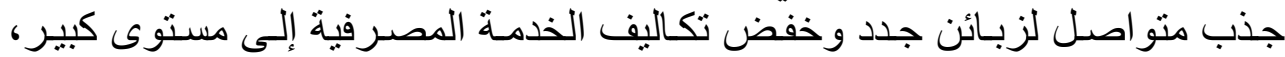

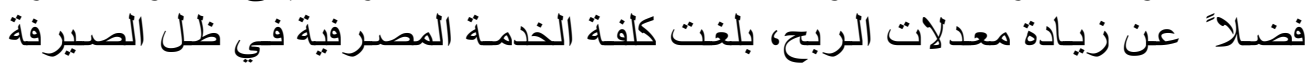

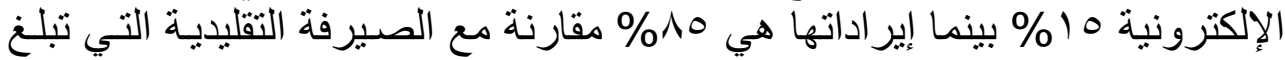

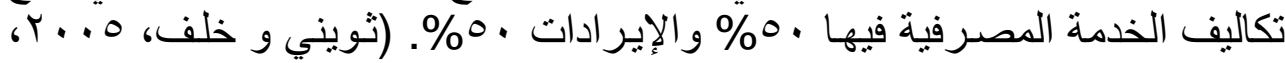




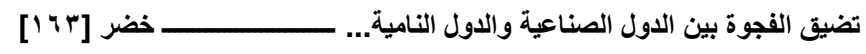

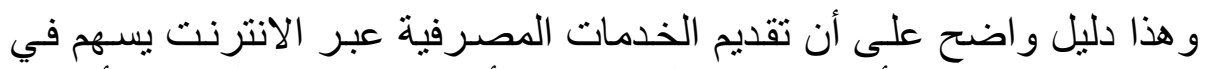
تخفيض النفقات وتعظيم الأرباح من خلال تقليص الأيدي العاملة ويقلل من الأخطاء

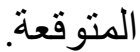

www.arabiyat.com/forums/showthread.php?s=8.thread.php?s=8threadid=29 $\underline{818}$

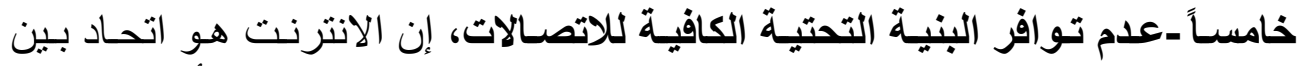

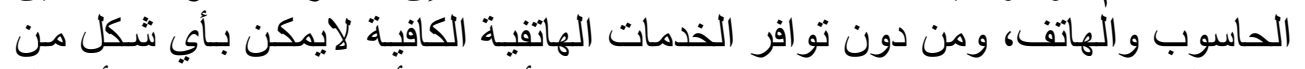

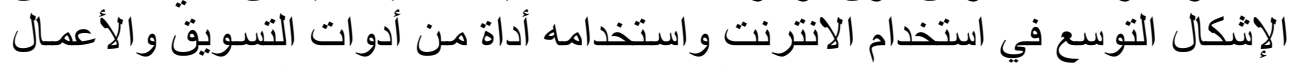
الإلكترونية، والخدمات الهاتفية لا تز ال محدودة في الكثير من الدول النئ النامية.

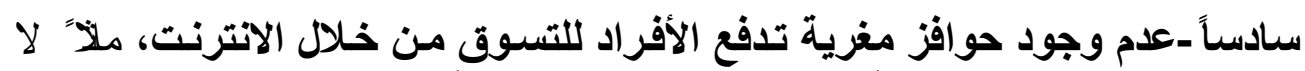
توجد فروق جوهرية في الأسعار عند التسوق التقلبدي أو التسوق عبر التبر الانترنت في لانتي

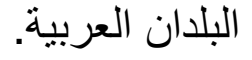

سابعاً ـ عدم توافر الوعي الكافي، فلا تزال الدول النامية تعاني من عدم تو افر الوعي

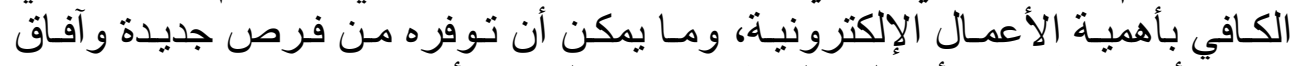

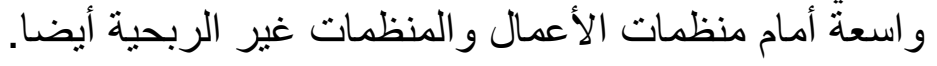

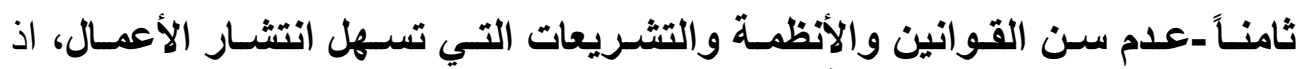

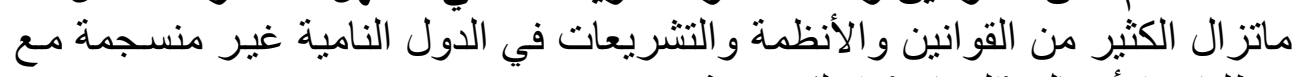
منطلبات الأعمال (التجارة) الإلكترونية.

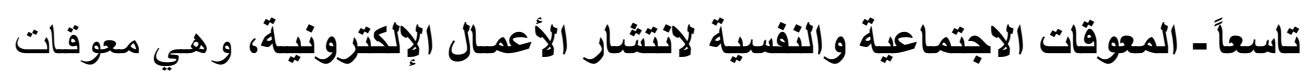

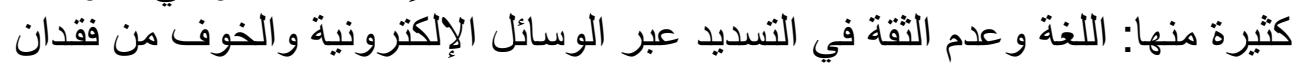

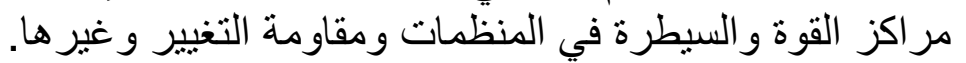

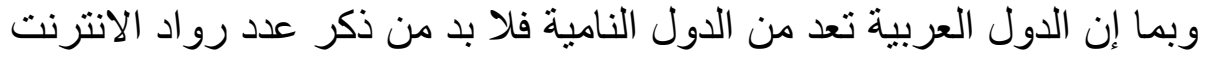

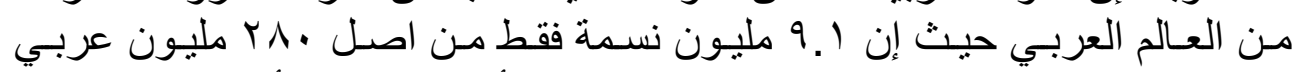

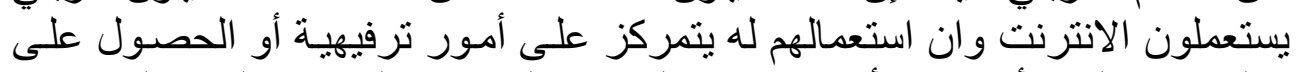

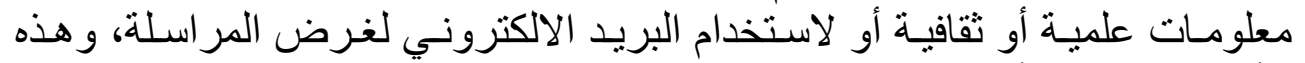

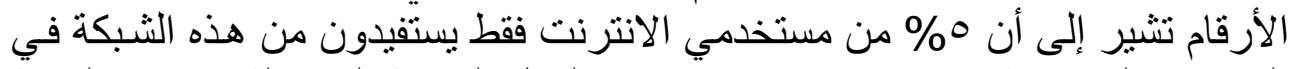

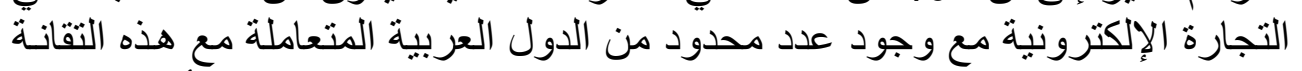

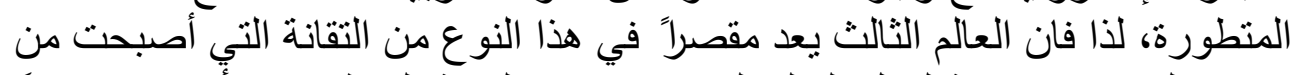

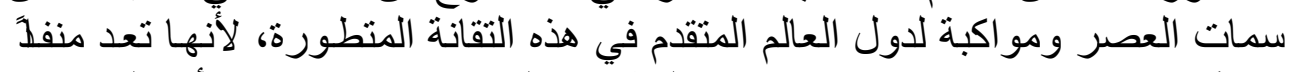

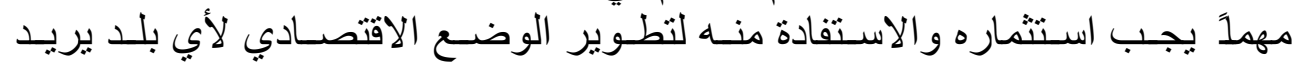

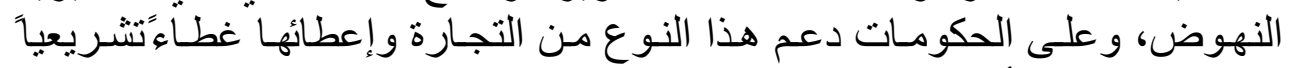

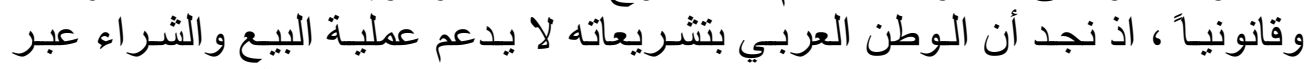

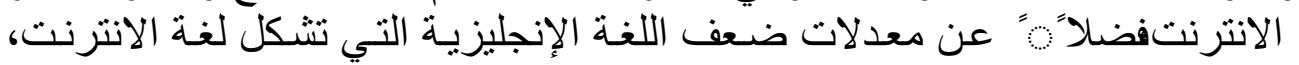




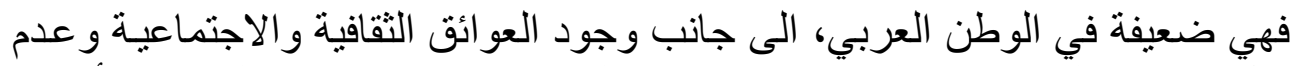

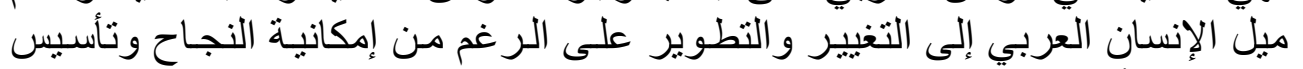

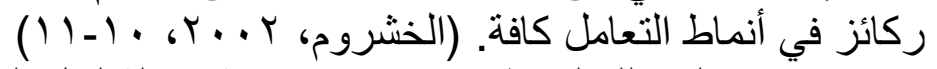

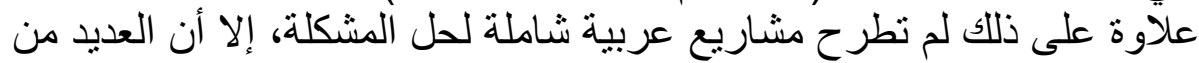

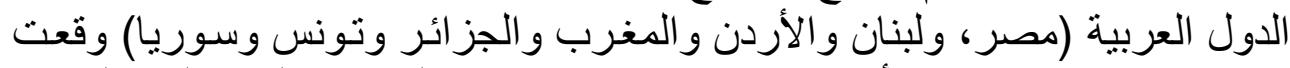

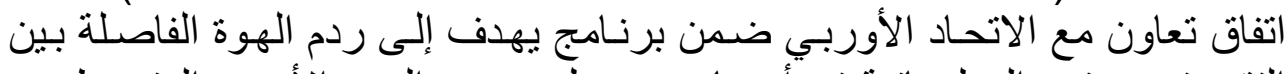

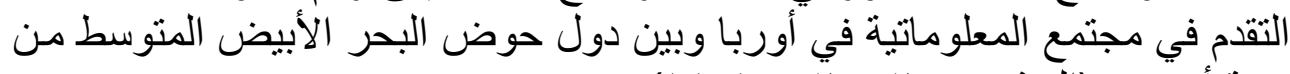

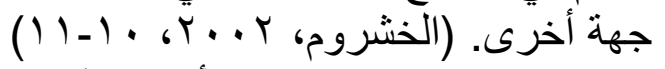

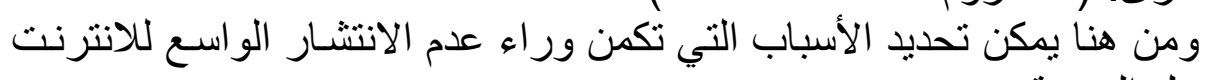

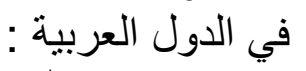

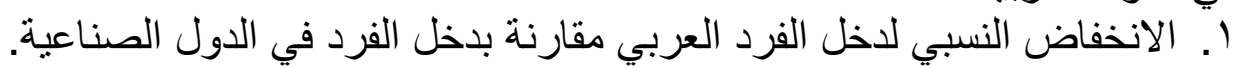

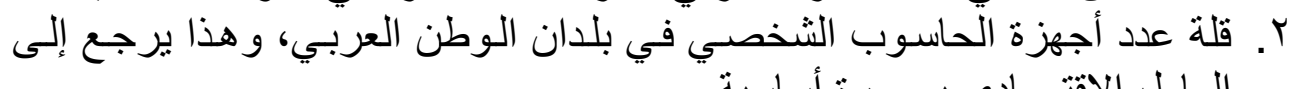

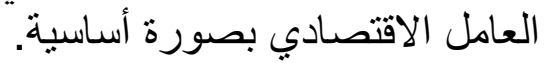

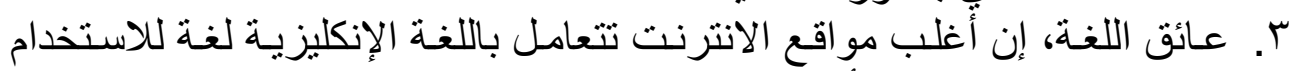

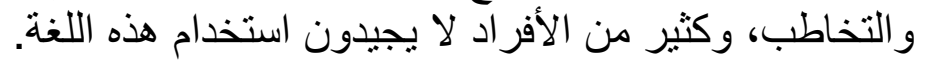

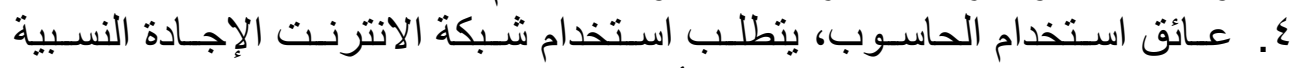

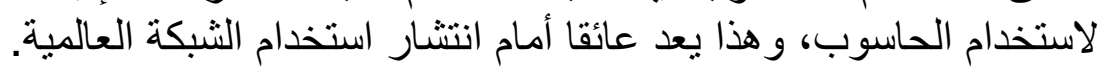

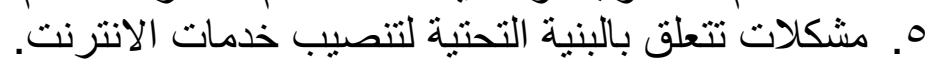

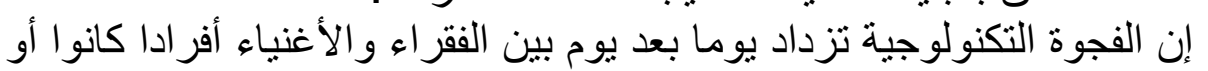

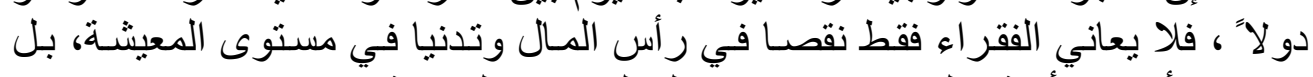

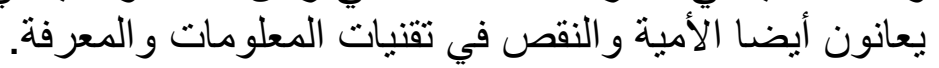

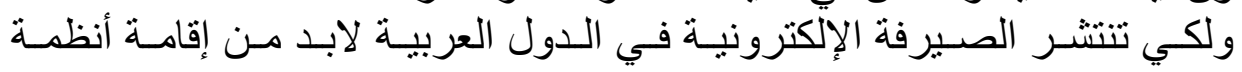

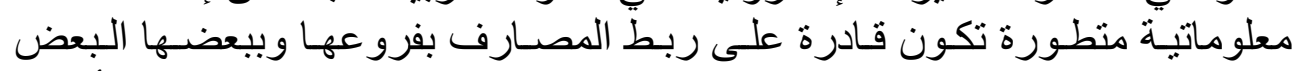

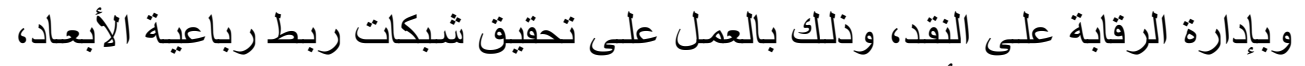

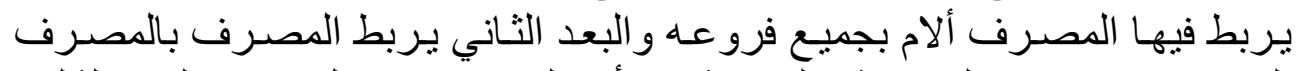

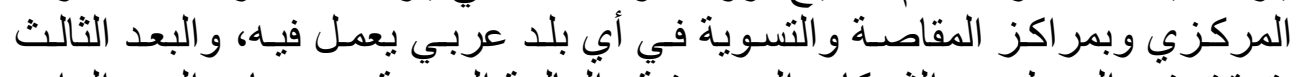

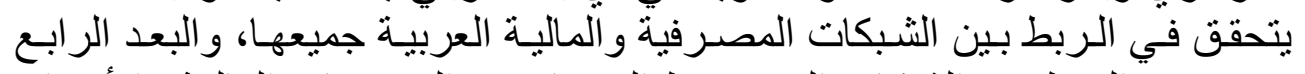

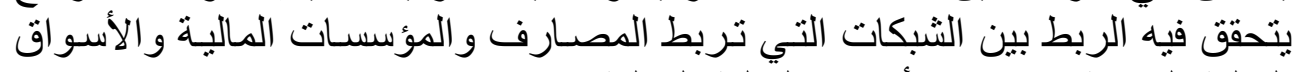

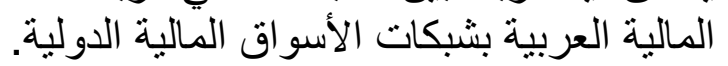

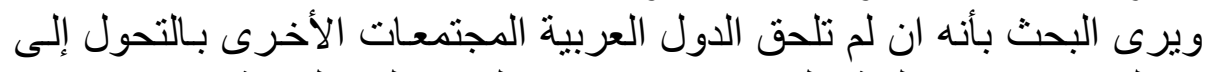

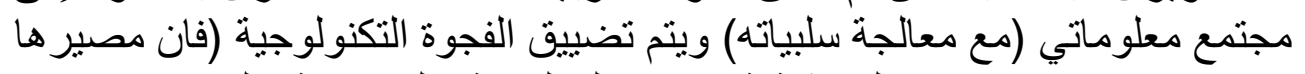

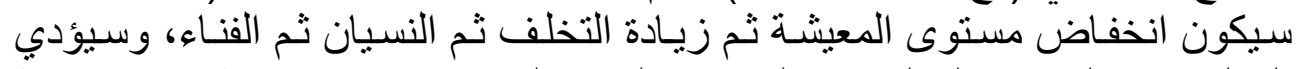
التخلف عن المجتمع المعلوماتي إلى تفاقم الفقر والمشكلات الاجتماعيـة و الاقتصـادية ليس في المجتمعات العربية فقط بل في العبو العالم أجمع. 
في ظل التطورات المتسار عة في الاقتصـاد و التغير ات التي تعكسها متطلبـات

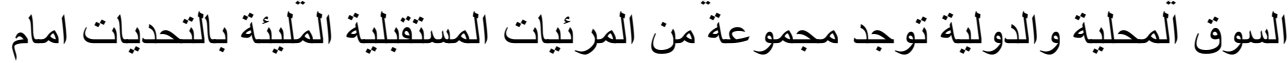

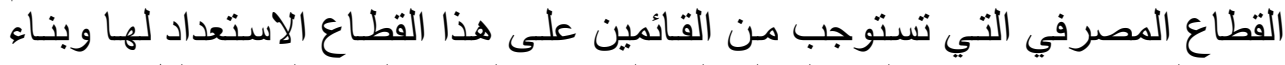

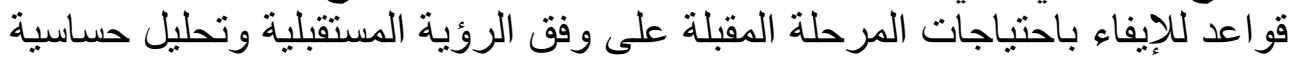

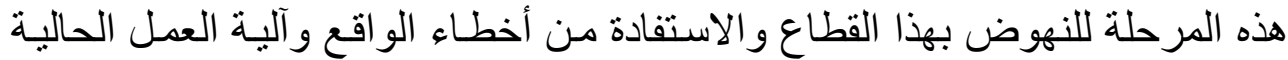

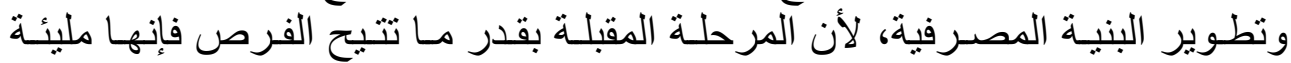

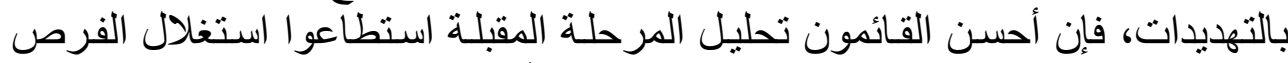

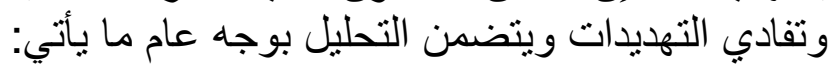

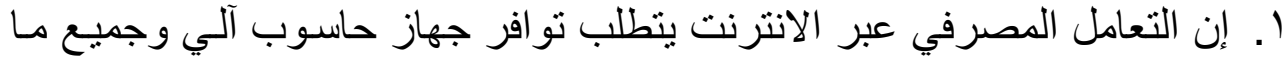

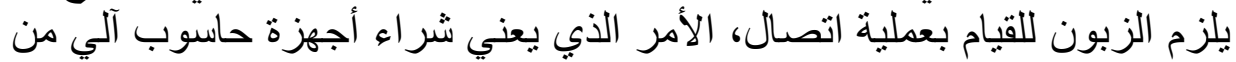

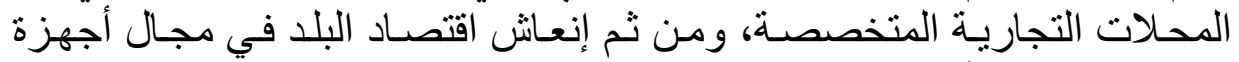

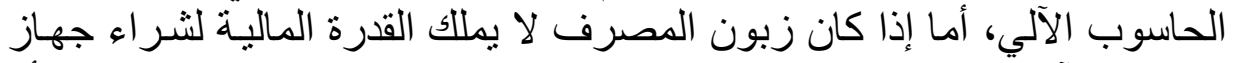

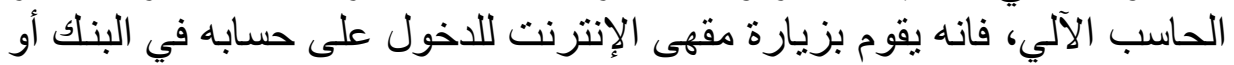

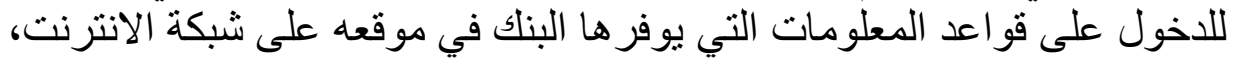

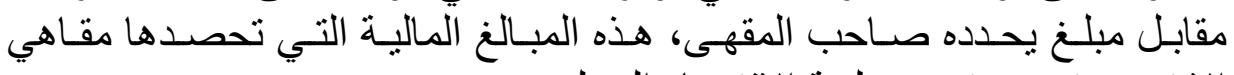

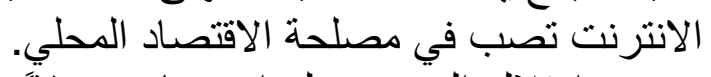

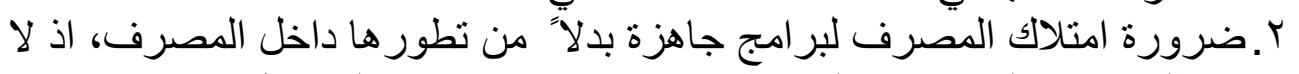

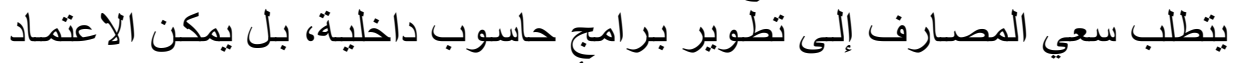

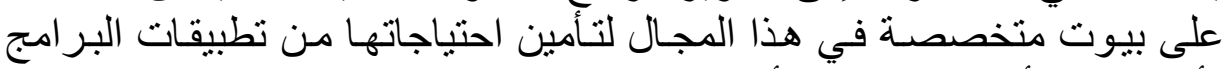

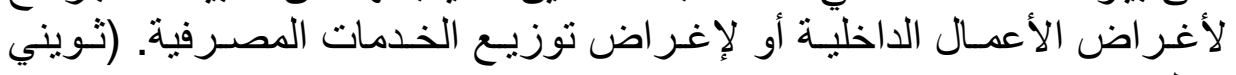

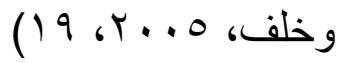

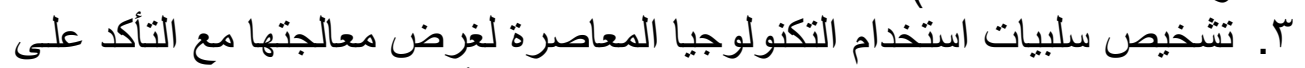

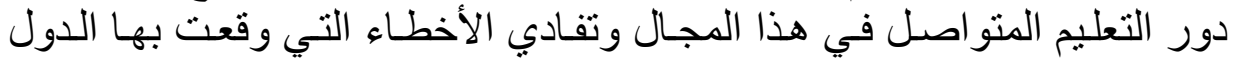

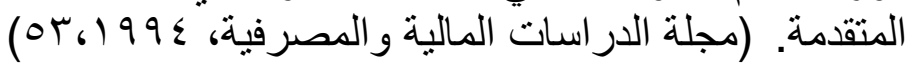

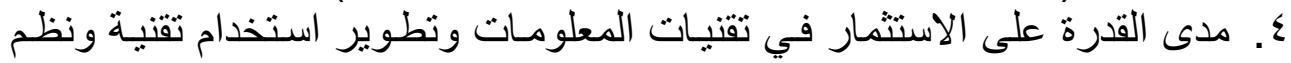

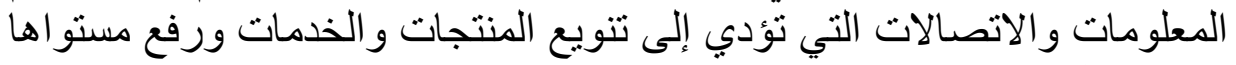
وتحقيق النمو.

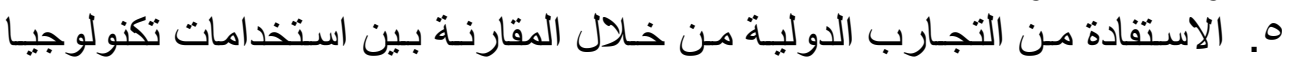

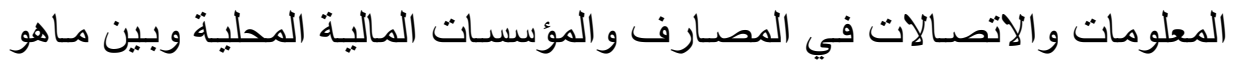

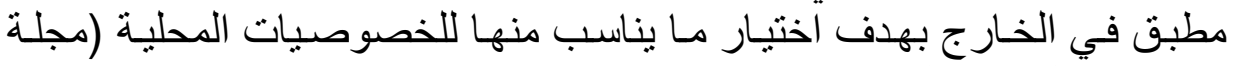

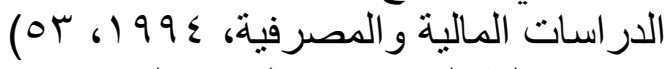

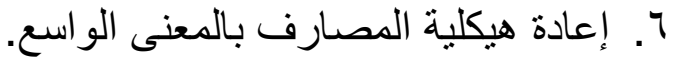

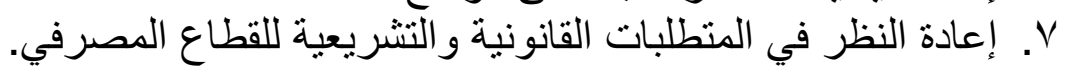

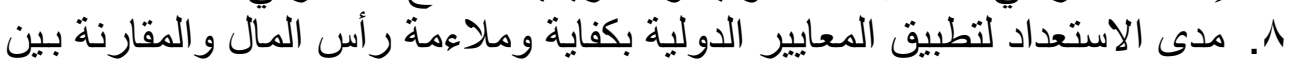


9. اختيار الآلات التي يتم بوساطتها تنفيذ النظام بالإضافة إلى اختبار آليات الاتصال

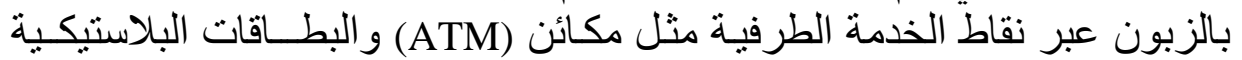

(Plastic Card)

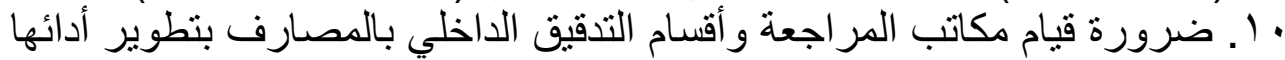

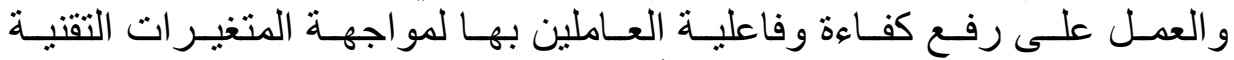

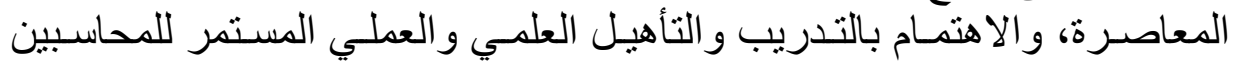

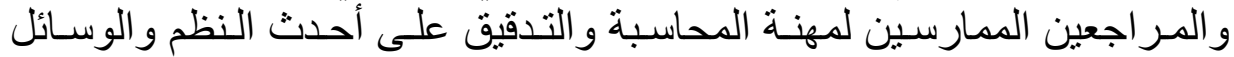

التكنولوجية المتقدمة من أجل رفع مهار اتهم وزيادة خبر اتهم العلمية والعملية. (www.al-watan.com/data/20050907/index.asp?content=ecs4)

\section{الاستنتاجات والتوصيات | الاستنتاجات}

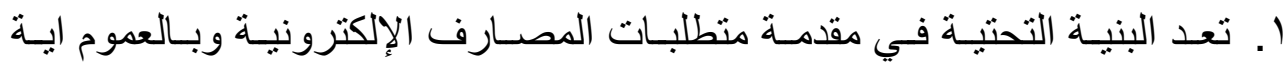

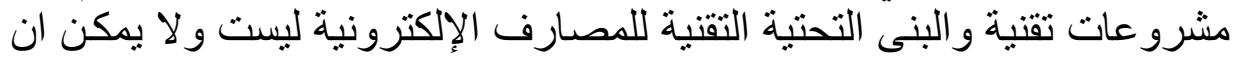

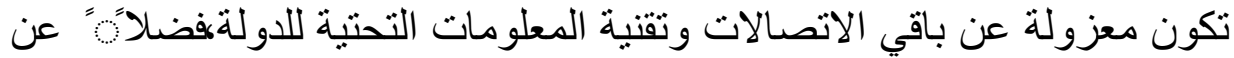
أن البنية التحتية التقنية العاملة في البلدان النامية ما زالت التئ غير قادرة على مواكبة

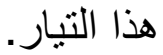

r. تعاني الدول النامية من عدم توافر الوعي الكافي بأهمية الأعمال الإلكترونية، وما

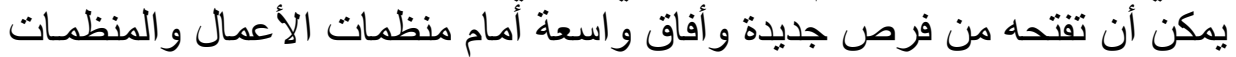

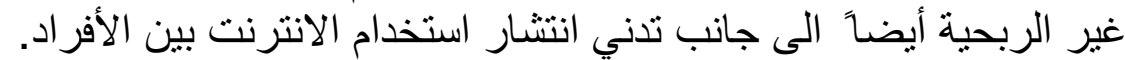

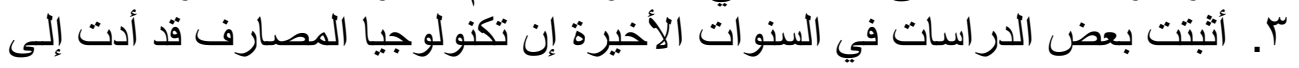

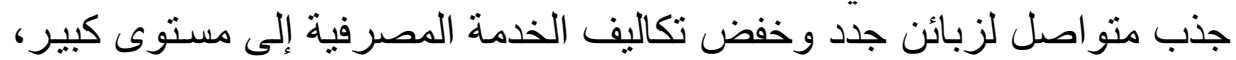

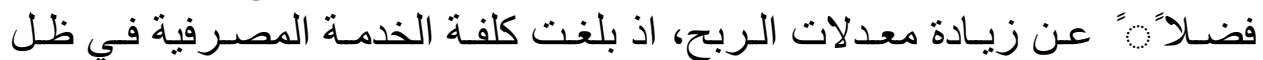

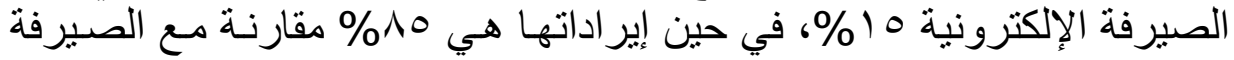

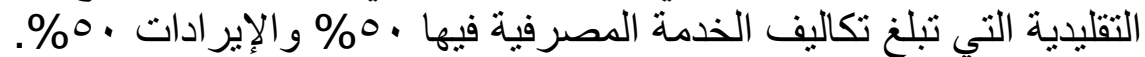

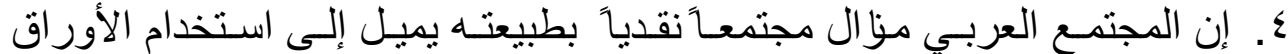

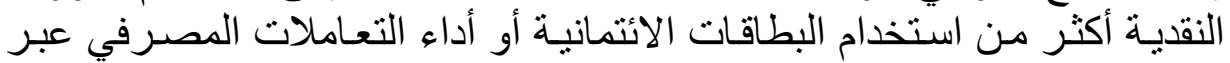

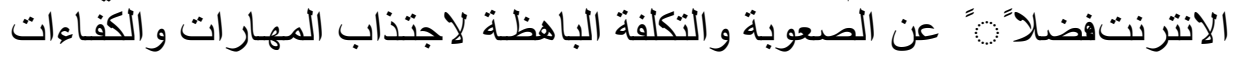

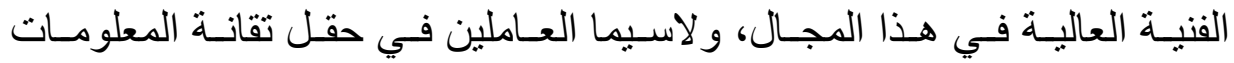

$$
\text { و الإنترنت و التجارة الإلكترونية. }
$$

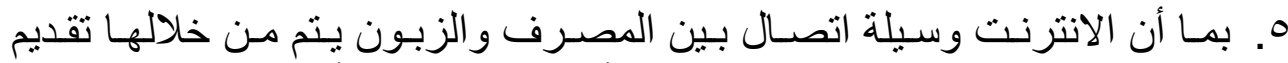

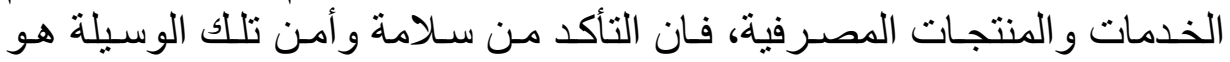

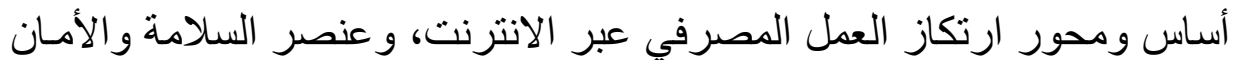

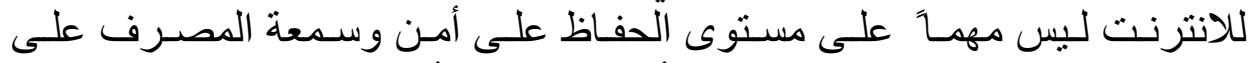

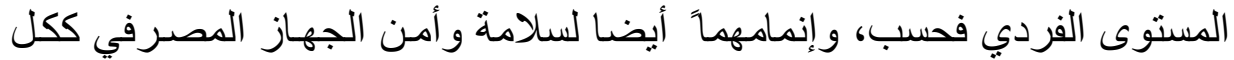
ولخلق الثقة العامة بهذا الجهاز من قبل الجمهور النيا لئرة 


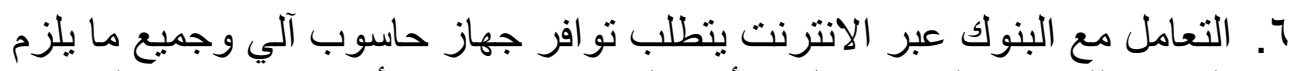

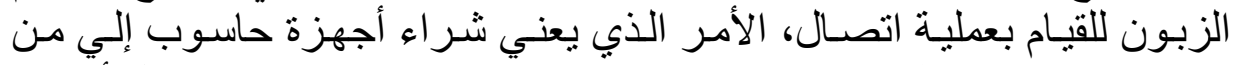

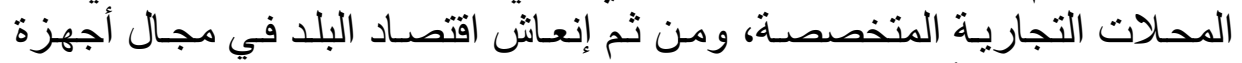

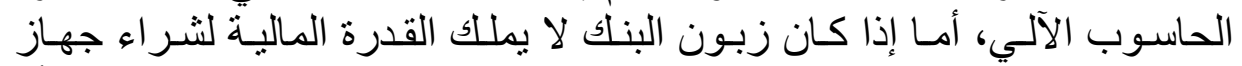

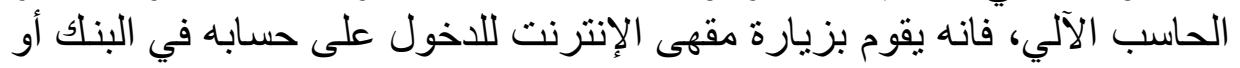

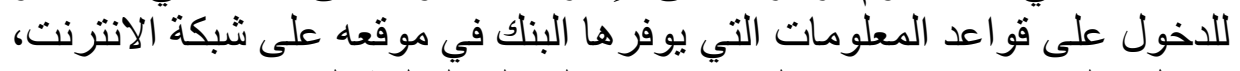

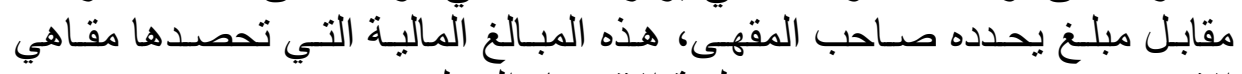

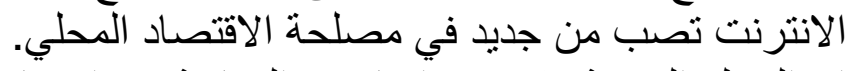

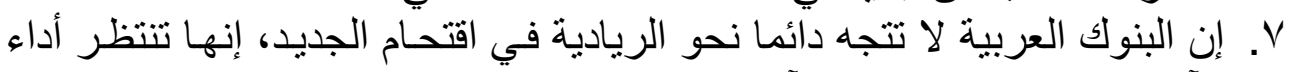

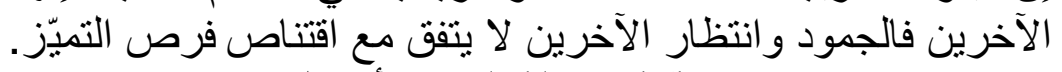

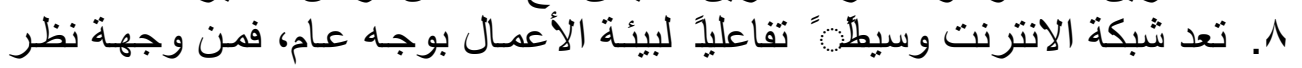

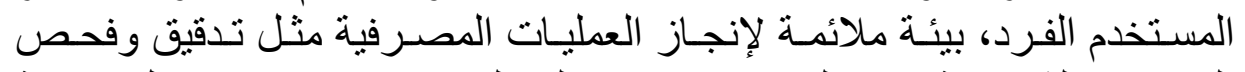

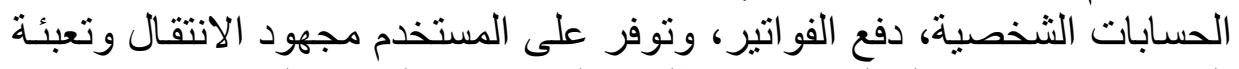

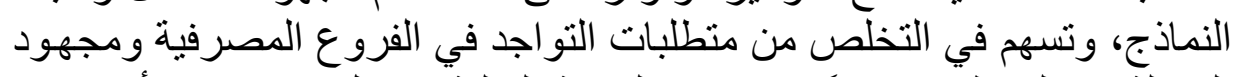

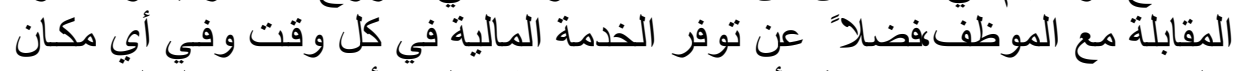

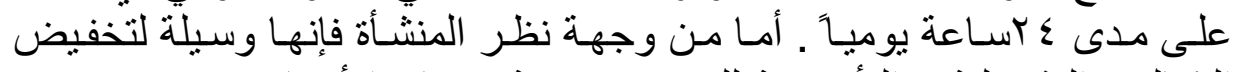

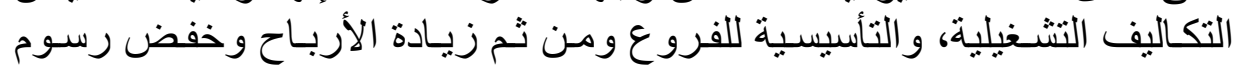

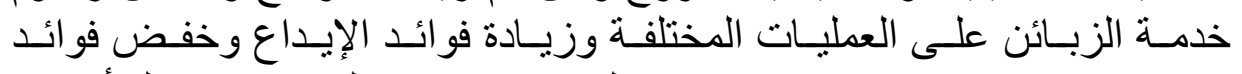

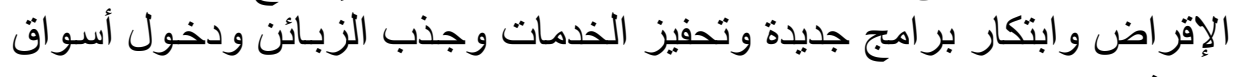
جديدة.

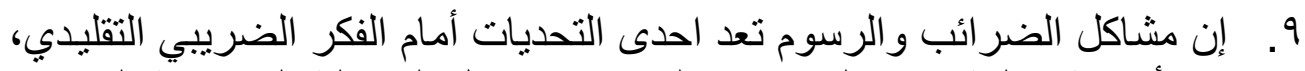

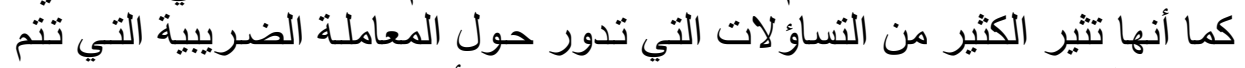

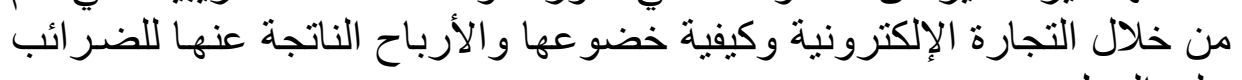

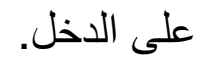

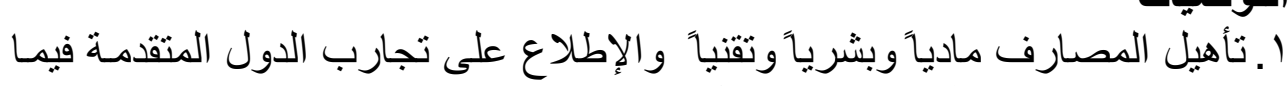

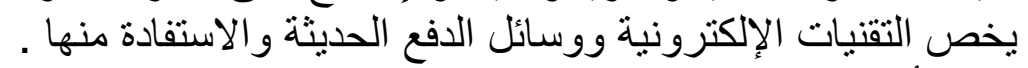

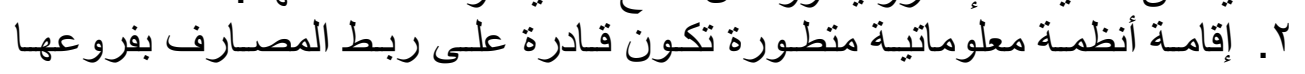

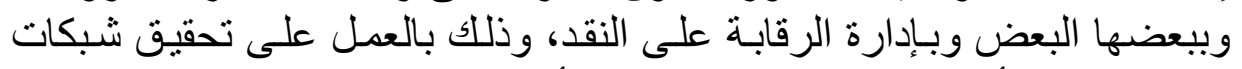

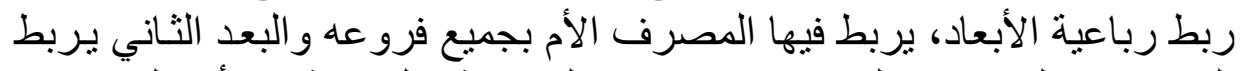

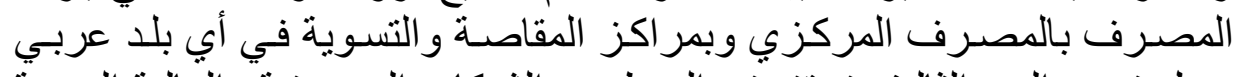

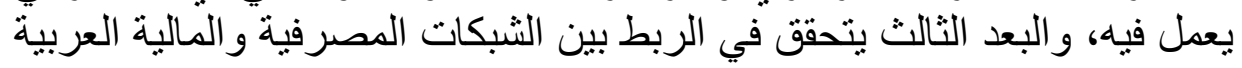

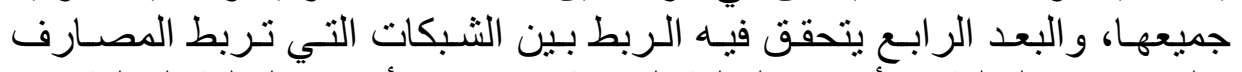

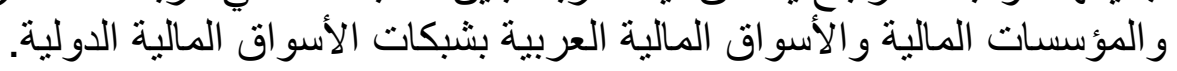

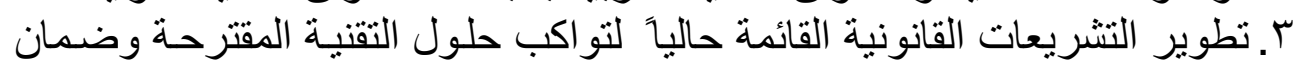
الالتز ام بتطبيقها. 
ع. ضرورة قيام مكاتب المر اجعة وأقسام التدقيق الداخلي بالمصسارف بتطوير أدائها

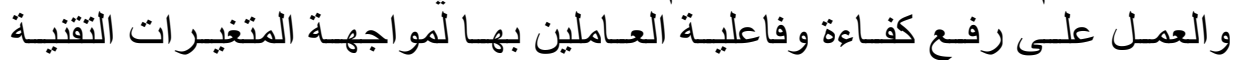

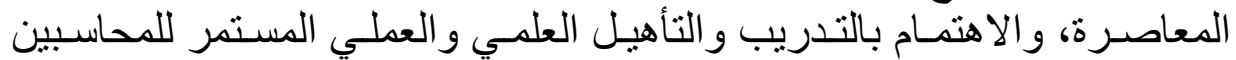

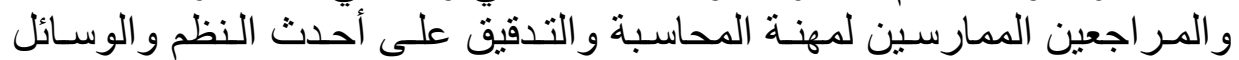
التكنولوجية المتقدمة من أجل رفع مهار اتهح وزيادة خبر اتهم العلمية و العملية.

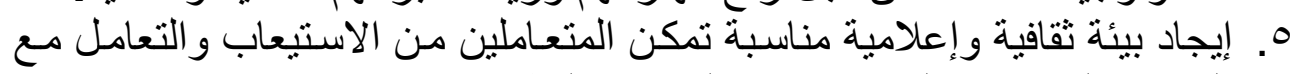

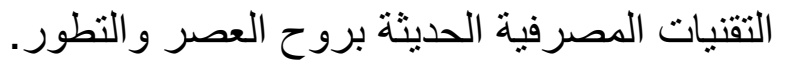

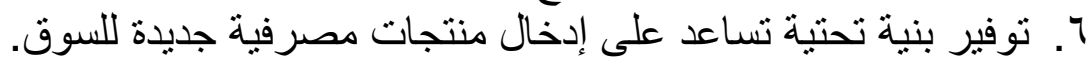

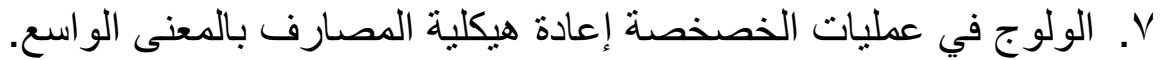

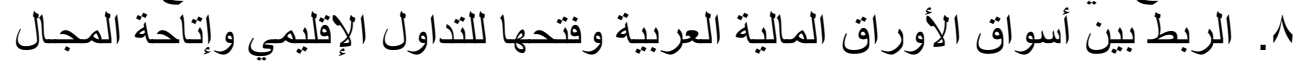

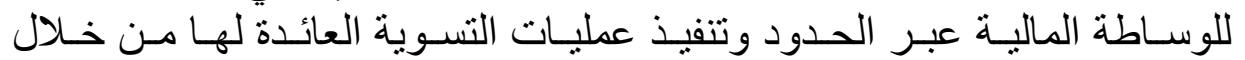
مؤسسات إقليمية. 9. تحسين مستوى الثفافية ودرجة الإفصاح المالي واعتماد المعايير الدولية المقبولة عند نشر الإحصاءات و والبيانات.

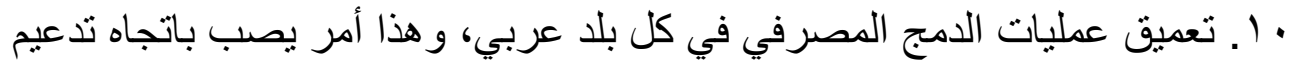

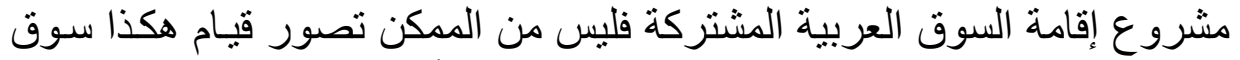

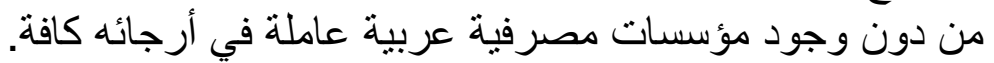

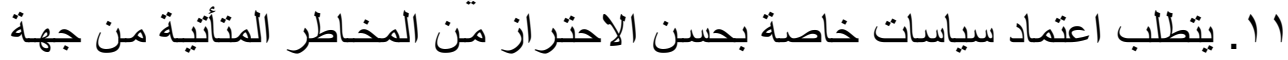

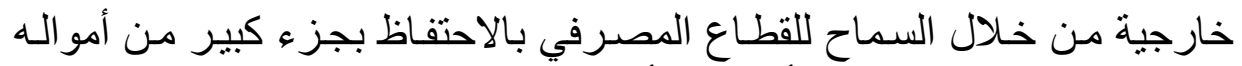

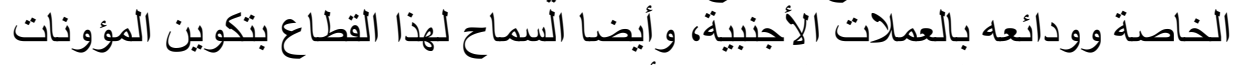

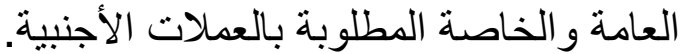

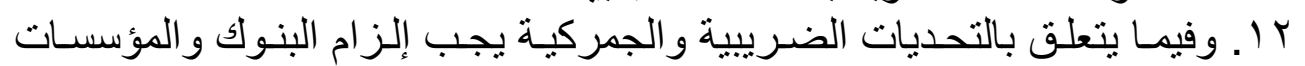

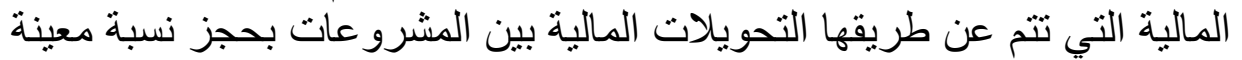

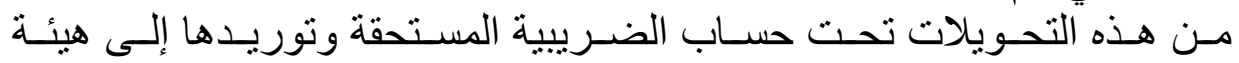

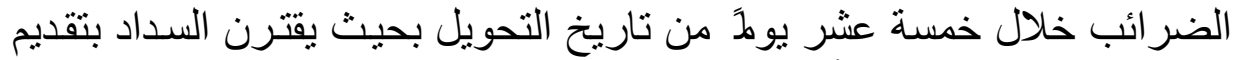

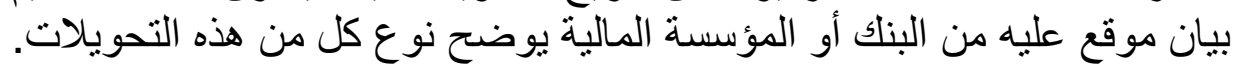

ا المراجع

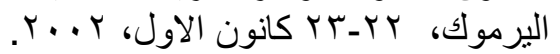

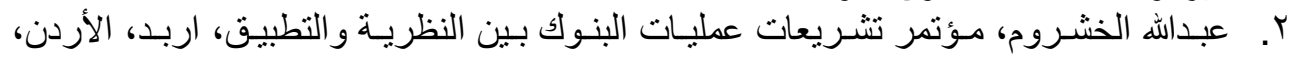

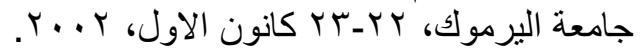

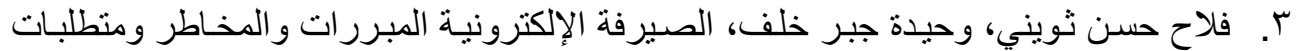

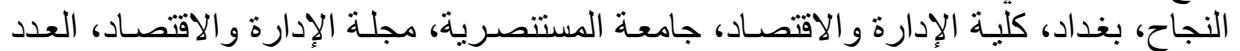

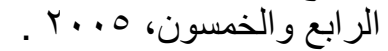

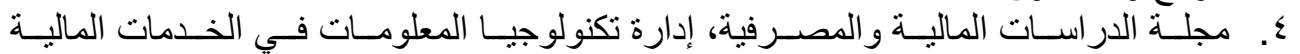

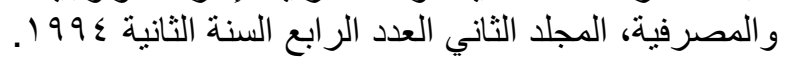




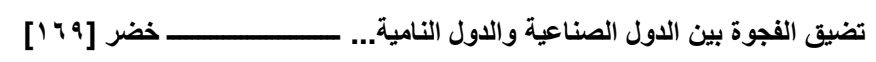

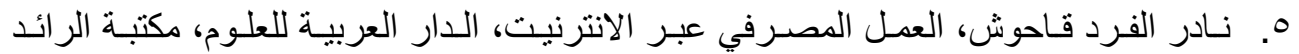

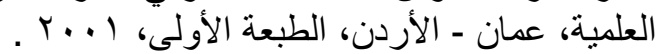

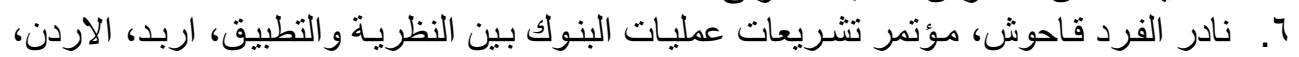

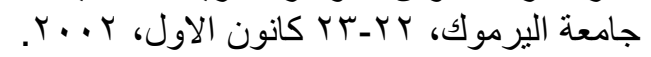

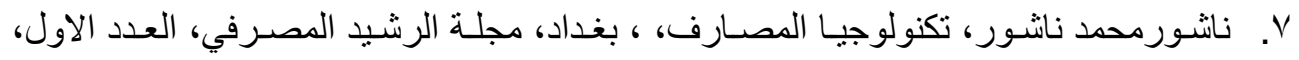
.r...

1. www.arablaw.org/-Banking.htm

2. www.arablaw.org/Download/E-Banking.doc

3. www.cbe.org.eg/public/regulations $\% 20$ of $\% 20$ the $\% 20$ Electronic $\% 20$ Banking $\% 20$ opera tions.doc

4. www.arabiyat.com/forums/showthread.php?s=8.thread.php?s=8threadid=29818

5. www.al-watan.com/data/20050907/index.asp?content=ecs4 